\title{
Real-time Modeling and Testing of Microgrid Management System for the Blue Lake Rancheria - Performance Assurance Report
}

Manish Mohanpurkar, Ph.D.

Yusheng Luo, Ph.D.

Rob Hovsapian, Ph.D.

Anudeep Medam

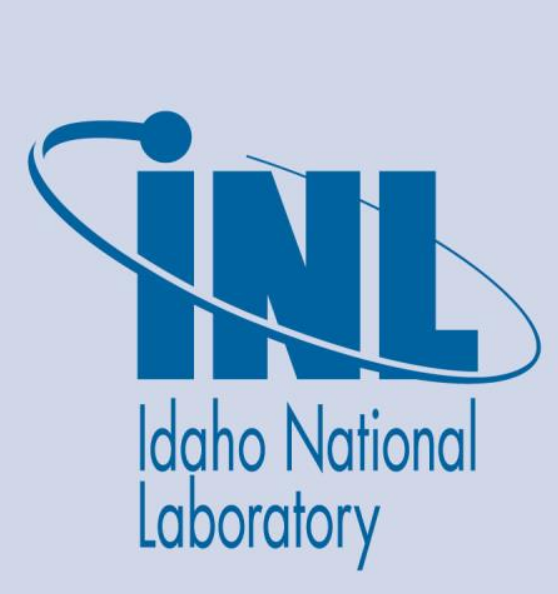

November 2017

The INL is a U.S. Department of Energy National Laboratory operated by Battelle Energy Alliance 


\section{DISCLAIMER}

This information was prepared as an account of work sponsored by an agency of the U.S. Government. Neither the U.S. Government nor any agency thereof, nor any of their employees, makes any warranty, expressed or implied, or assumes any legal liability or responsibility for the accuracy, completeness, or usefulness, of any information, apparatus, product, or process disclosed, or represents that its use would not infringe privately owned rights. References herein to any specific commercial product, process, or service by trade name, trade mark, manufacturer, or otherwise, does not necessarily constitute or imply its endorsement, recommendation, or favoring by the U.S. Government or any agency hereof. The views and opinions of authors expressed herein do not necessarily state or reflect those of the U.S. Government or any agency thereof. 


\section{Contents}

ACRONYMS viii

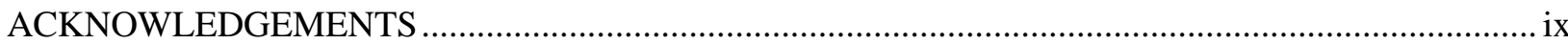

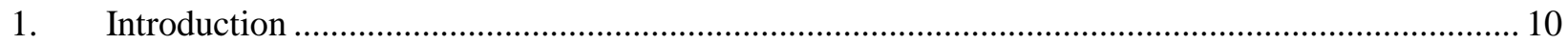

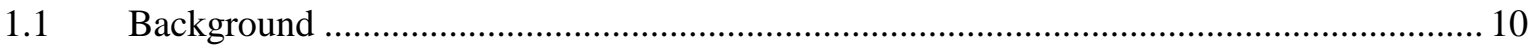

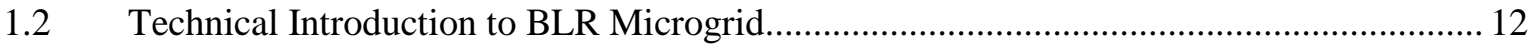

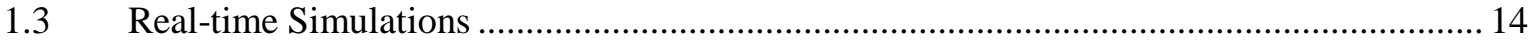

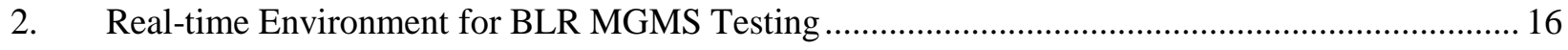

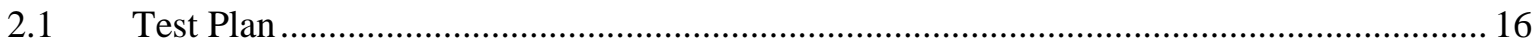

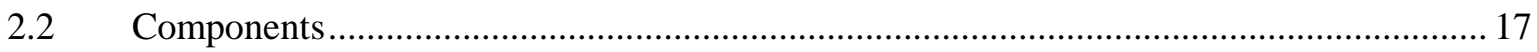

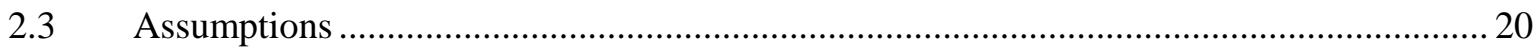

3. Test Procedures for MGMS Unit and Functionality Testing...................................................... 22

4. Test Procedures - Secondary Protection without MGMS............................................................. 25

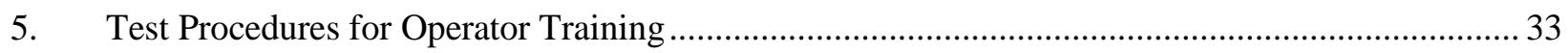

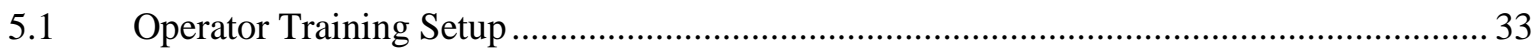

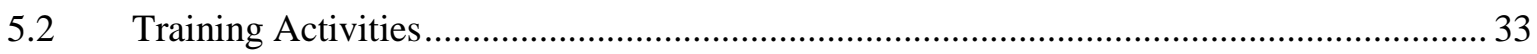

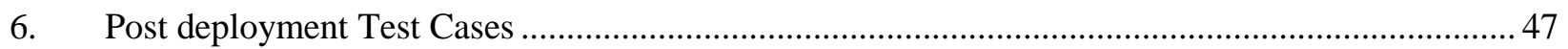

6.1 Failure of BESS Frequency and Voltage Regulation by MGMS .................................... 47

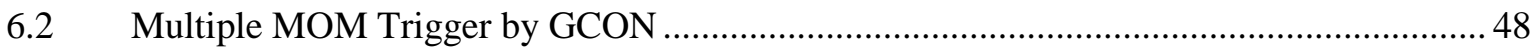

6.3 Failure to Trigger MOM by GCON during Manual Black Start ...................................... 50

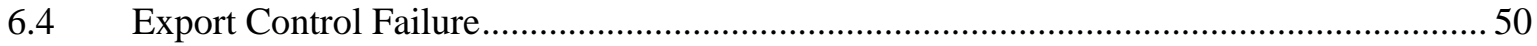

6.5 Regression Test to Check the Working of SOEs........................................................... 50

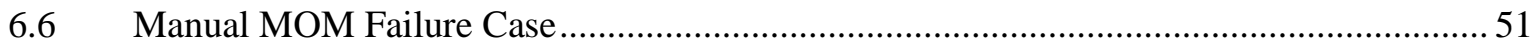

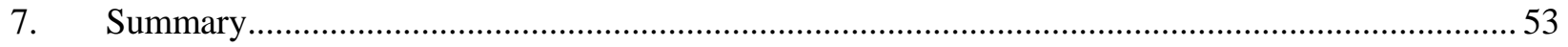

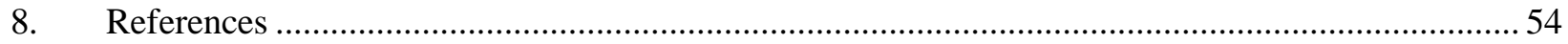




\section{LIST OF FIGURES}

Figure 1- Blue Lake Rancheria Site for the MG development ......................................................... 11

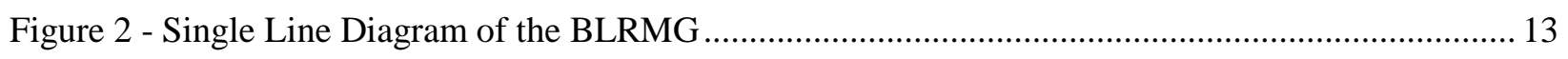

Figure 3 - BLRMG Test setup at the Power and Energy Real-time Laboratory, INL ............................. 17

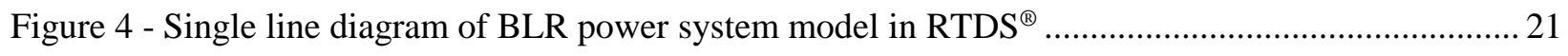




\section{LIST OF TABLES}

Table 2 - List of loads

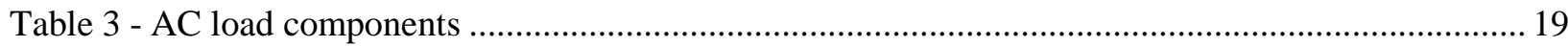

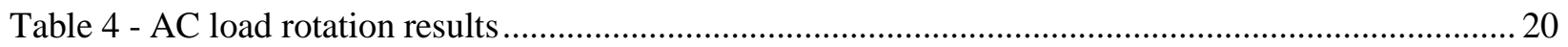

Table 5 - Test results for transition to islanded operations after MGMS non-response …....................... 25

Table 6 - Test results for transition to islanded operations with MGMS offline …................................26

Table 7 - Test results for successful reconnection after 15 minutes of PG\&E grid stability .....................227

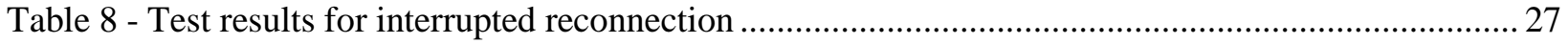

Table 9 - Test results for manual disconnect from PG\&E grid due to relay button press .......................28

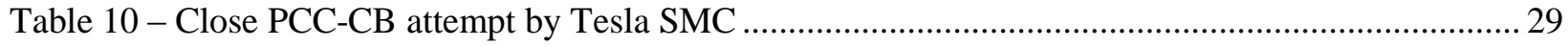

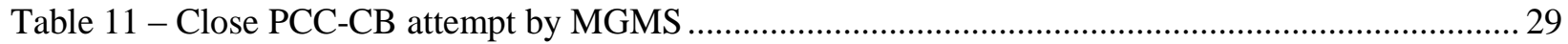

Table 12 - Close attempt by operator using SEL700GT+ close push button........................................ 29

Table 13 - Disconnect of diesel generator using pushbutton while islanded .......................................... 30

Table 14 - Disconnect of diesel generator using pushbutton while islanded .......................................... 31

Table 15 - Disconnect of diesel generator using pushbutton while islanded ........................................... 31

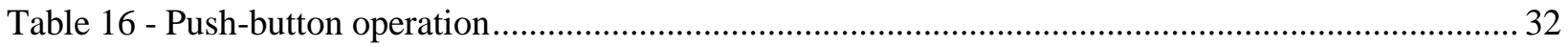

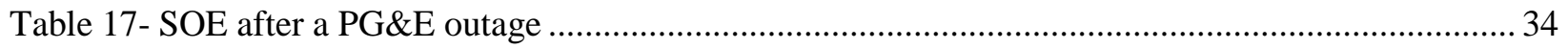

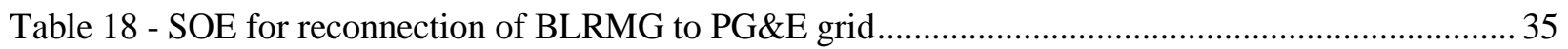

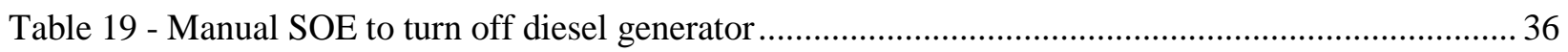

Table 20 - SOE for reconnection sequence with BLRMG islanded with BESS....................................... 37

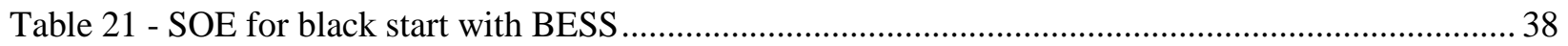

Table 22 - SOE for diesel generator failure to come online with BESS .................................................. 39

Table 23 - SOE for successful connection of diesel generator to islanded BLRMG with BESS .............. 40

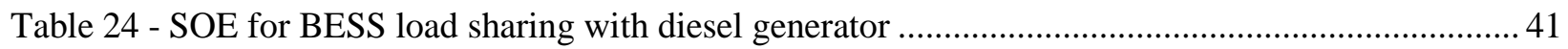

Table 25 - SOE for reconnection to PG\&E grid from islanded BLRMG with BESS and PV .................. 42 
Table 26 - SOE for PG\&E grid outage with diesel generator and BESS available.....

Table 27 - Events that would occur after a PG\&E grid outage with MGMS offline............................... 44

Table 28 - SOE for reconnection from islanded BLRMG with MGMS offline earlier ............................ 45

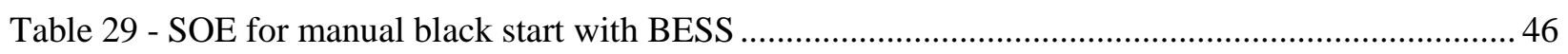




\section{ACRONYMS}

AC: Air Conditioning

ATS1: Automatic Transfer Switch for 1MW diesel generator

BESS: Battery Energy Storage System

BLR: Blue Lake Rancheria

CEC: California Energy Commission

CPUC: California Public Utilities Commission

CHIL: Controller-Hardware-In-the-Loop

DER: Distributed Energy Resources

DNP3: Distributed Network Protocol communications protocol

DRTS: Digital Real-Time Simulator

GCON: Generation Control

GM: Generation Management

HIL: Hardware-In-the-Loop

HSU: Humboldt State University

IEEE: Institute of Electrical and Electronics Engineers

INL: Idaho National Laboratory

LT: Latched bit used within relays for capturing signals in the relay

MG: Microgrid

MGMS: Microgrid Management System

MODBUS: A serial communication protocol

MOM: Microgrid Optimization Module

P: Active power

PCC: Point of common coupling

PCCCB: PCC circuit breaker

PG\&E: Pacific Gas \& Electric

PHIL: Power-Hardware-In-the-Loop

PQ mode: real-reactive power mode of the battery

PV: Photovoltaic

Q: Reactive power

RTDS $^{\circledR}$ : Real Time Digital Simulator

SERC: Schatz Energy Resource Center

SEL: Schweitzer Engineering Laboratories

SMC: Site master controller

SOC: State of charge

SOE: Sequence of Events

UL: Underwriters Laboratories

VF mode: voltage-frequency mode of the battery 


\section{ACKNOWLEDGEMENTS}

We highly appreciate the funding opportunity provided by the California Energy Commission to perform this work. Additionally, we would like to thank the following individuals for their contributions to the overall project effort, testing, use case development, and this summary report.

\begin{tabular}{|c|c|c|}
\hline Serial no. & Name & Organization \\
\hline 1 & Cliff Loughmiller & Idaho National Laboratory \\
\hline 2 & Fernando Dias & Idaho National Laboratory \\
\hline 3 & Doug Saucedo & Schatz Energy Research Center \\
\hline 4 & Dr. Peter Lehmann & Schatz Energy Research Center \\
\hline 5. & Jim Zoellick & Schatz Energy Research Center \\
\hline 6 & David Carter & Schatz Energy Research Center \\
\hline 7 & Marc Marshall & Schatz Energy Research Center \\
\hline 8 & Shashank Pande & Siemens \\
\hline 9 & Ali Afdjeie & Siemens \\
\hline 10 & Sanath Prabhu & Siemens \\
\hline 11 & Ye Ma & Siemens \\
\hline 12 & Jana Ganion & Blue Lake Rancheria \\
\hline 13 & Neil Harris & Blue Lake Rancheria \\
\hline 14 & Randy Cox & Blue Lake Rancheria \\
\hline 15 & Robert Pollard & Blue Lake Rancheria \\
\hline 16 & Heath Hilton & Blue Lake Rancheria \\
\hline 17 & Eric Bailey & Blue Lake Rancheria \\
\hline
\end{tabular}




\section{Introduction}

\subsection{Background}

"Demonstrating a Secure, Reliable, Low Carbon Community Microgrid at the Blue Lake Rancheria" was funded by the California Energy Commission (CEC) under the California Energy Commission Electric Program Investment Charge PON-14-301. The prime recipient of this award was the Schatz Energy Research Center (SERC), Humboldt State University (HSU). Idaho National Laboratory (INL) was a team member on this project and provided lab facilities to thoroughly test the Microgrid Management Systems (MGMS) built by Siemens.

The goal of this project was to build a renewable and self-sustaining microgrid for the Blue Lake Rancheria (BLR); a sovereign Native American Tribe located in northwestern California and is shown in Figure 1. A microgrid (MG) is defined as, "a group of interconnected loads and distributed energy resources within clearly defined electrical boundaries that acts as a single controllable entity with respect to the grid. A microgrid can connect and disconnect from the grid to enable it to operate in both grid-connected or island mode" [1]. The project addresses and promotes important objectives outlined for California's energy system by the CEC.

- It will greatly increase the stability and resiliency of a portion of the state's electric grid. The microgrid solution for the BLR tribal land will be able to island and continue to supply electric power almost indefinitely if the larger grid is down.

- It will provide cost savings and reduce stress on the larger electric grid. By employing utility scale energy storage and sophisticated control, the microgrid will allow peak shaving, demand response, and load shedding to reduce costs and power fluctuations.

- It will provide for public health and safety during emergencies. The BLR is a nationally recognized American Red Cross critical support facility. This is crucial as the North Coast of California is an area especially susceptible to natural disasters, including earthquakes, tsunamis, floods, and wildfire. This microgrid system will ensure a longterm place of safety with continuing electric power in the event of an emergency.

- It will significantly increase the contribution of local renewable energy to the state's electric grid. The microgrid includes a new $420 \mathrm{~kW}$ photovoltaic (PV) array. Adding significant renewable power to the grid reduces greenhouse gas emissions and makes electric power at BLR even more secure. 


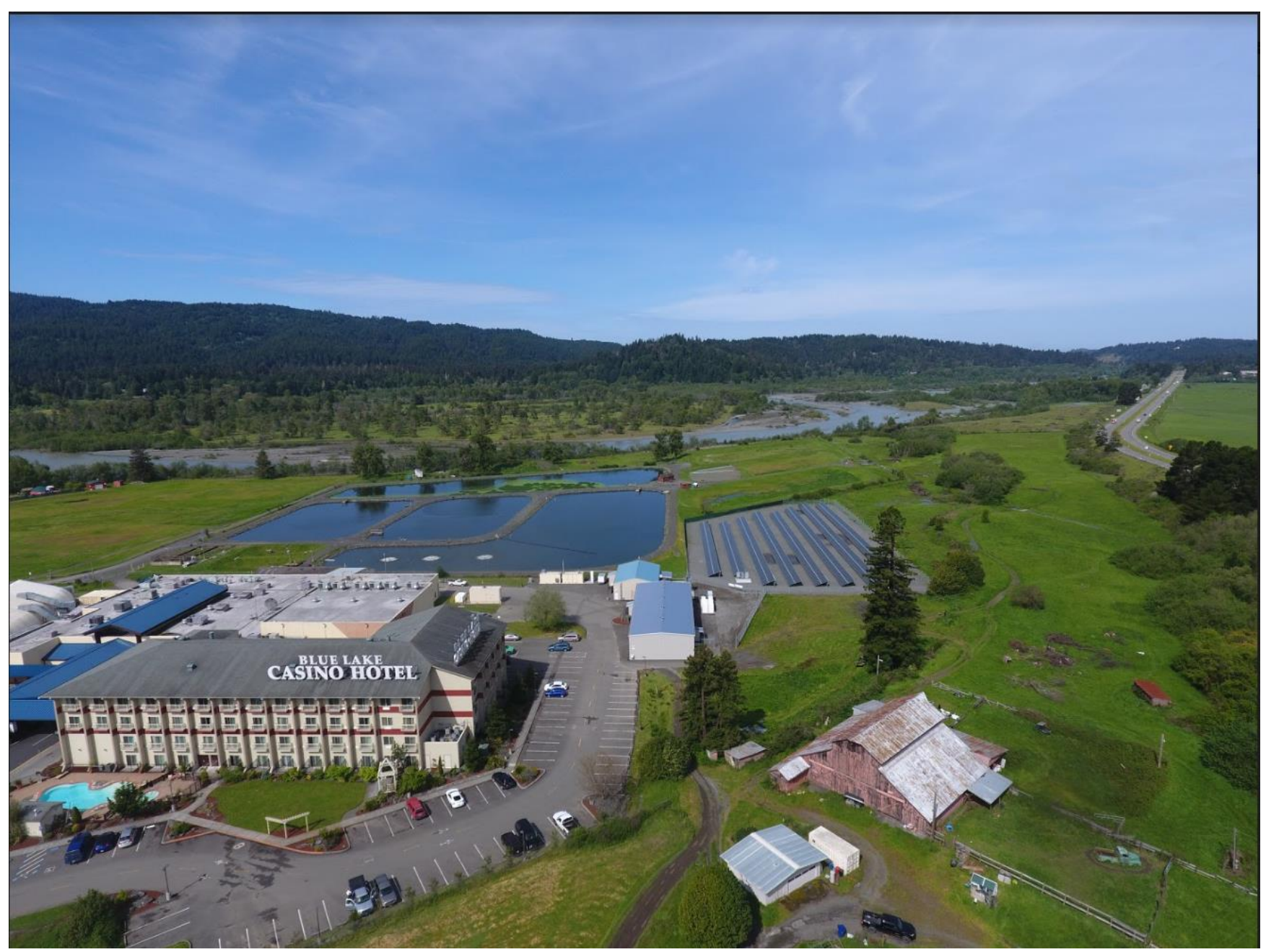

Figure 1- Blue Lake Rancheria site for the MG development 


\subsection{Technical Introduction to BLR Microgrid}

The Microgrid Management System (MGMS) developed by Siemens is installed onsite to manage the BLR microgrid (BLRMG) and was tested at INL for conformance of functionalities as well as to provide a robust opportunity to train BLR operators. The design and conformance of technical functionalities in the MGMS contribute directly to the overall project objectives as described in the earlier subsection. There are standards such as IEEE 2030.7, IEEE 2030.8, UL 3001 , etc. under formalization process that provide specific requirements of microgrids and MGMS functionalities and guidelines to test them. However, at the time of project execution these standards were still under development and therefore were not conformed to.

Several design objectives were considered while designing the BLRMG and MGMS emergency response benefits, economic benefits, environmental benefits, new distributed energy resource (DER) penetration, etc. The emergency response benefit is one of the key drivers to ensure availability of local energy and harness it to generate electricity such that the BLR facility loads are powered during unavailability of utility supply. The time duration for which an emergency response is expected from a MG is one of the key factors that affected the DERs selected for use. Other factors that affected DER selection were budget, resource availability, loads, etc. The PG\&E grid in this case forms the area electric power system. A single line diagram of the BLRMG is shown in Figure 2 below: 


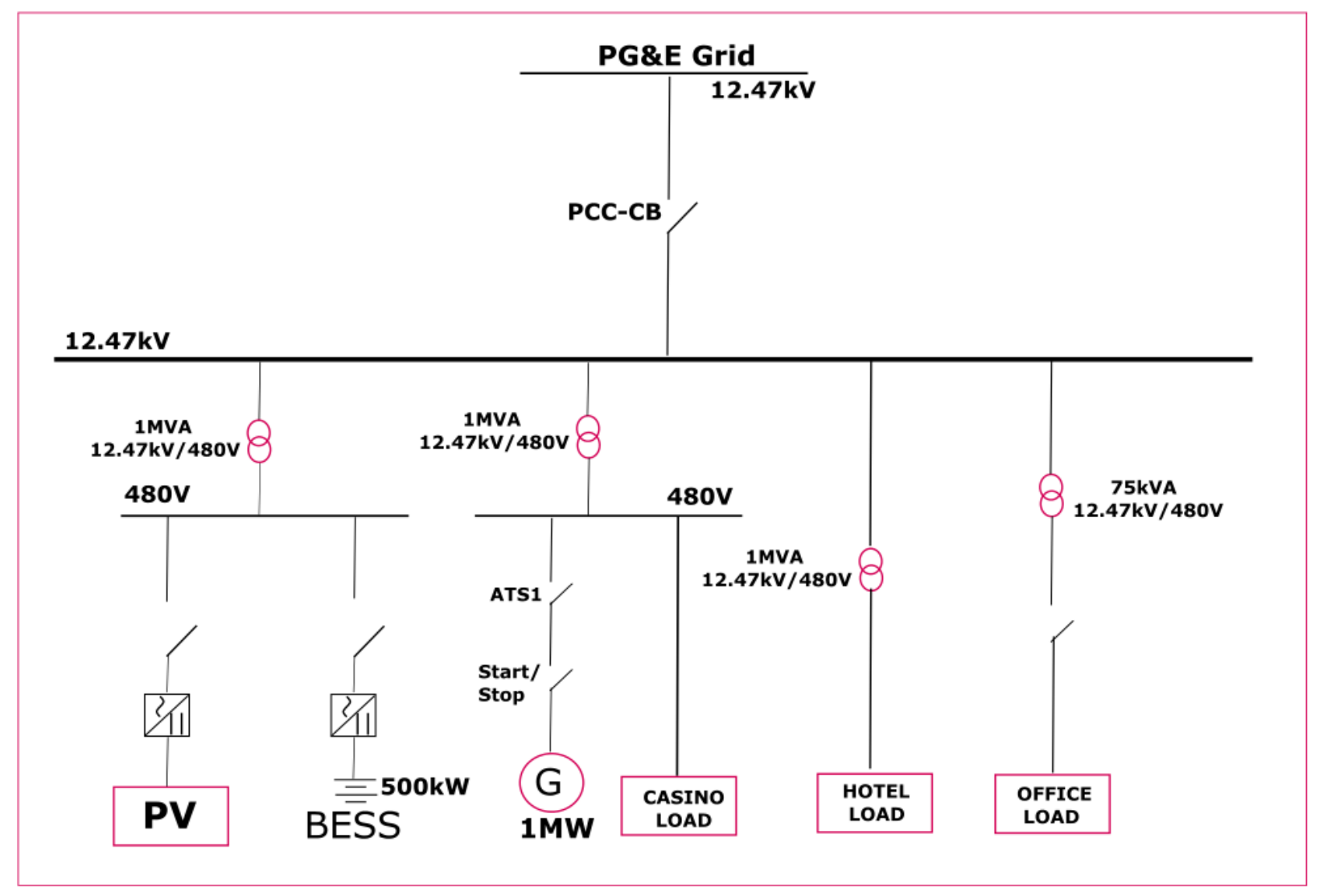

Figure 2- Single Line Diagram of the BLRMG

The BLR microgrid can connect to or isolate itself from the PG\&E grid and is capable of both seamless and "break-before-make" transitions; also it is reactive and active power can be controlled independently to meet the dynamic needs of the loads. Resilience by design approach has been adopted for the design of BLRMG. Each DER front-end controller must respond autonomously and effectively to system changes without requiring information from the loads, the static switch, or other sources. During islanded mode, the MGMS controller employs feedback control on frequency and voltage using real time values of active power $(\mathrm{P})$, reactive power $(\mathrm{Q})$, frequency, and ac voltage to generate the desired power output for each DER and voltage magnitude on the microgrid by using droop concepts. Droop control ensures that as the reactive power generated by the DER becomes more capacitive, the local voltage set point is reduced. Conversely, as Q becomes more inductive, the voltage set point is increased.

When the microgrid is connected to the grid, loads receive power both from the grid and from local DERs, depending on the optimization objective. If the grid power is lost because of voltage sags, faults, blackouts, etc., the microgrid autonomously switches to islanded operation. If the system is switched to island mode then the DERs need to increase the power generation to balance loads in the island. 


\subsection{Real-time Simulations}

INL's one-of-a-kind facility - Power and Energy Real-time Laboratory, has a diverse set of digital real-time simulator (DRTS) and other capabilities that allow rapid prototyping of controllers, device integration, and de-risking of novel control algorithms and energy devices. A commercially available DRTS, the Real Time Digital Simulator (RTDS ${ }^{\circledR}$ ) was used to perform the rigorous testing of the MGMS with Hardware-In-the-Loop (HIL). HIL included a PV array and associated inverter, as well as protective relays. The rest of the BLRMG was digitally simulated. RTDS ${ }^{\circledR}$ performs simulations of power systems using an electromagnetic transienttype program being integrated with advanced processor boards. It accomplishes the task of realtime simulation via parallel computation. It uses trapezoidal integration to determine the solutions at the end of each time-step of $50 \mu$ s or so [1-2]. Such small time-steps enabled us to accurately and reliably simulate power system phenomena in the range of 0 to $3 \mathrm{kHz}$ [1-3]. The important feature of most commercially available DRTS is the ability to perform HIL [4-7]. Based on the interface and integration of devices with DRTS, there are two kinds of HIL simulation.

The subsequent sections of this report provide greater details of the testing efforts with relevant results assuring verification and validation of functionalities of the MGMS. HIL capabilities, including Controller-HIL (CHIL) and Power-HIL (PHIL) were used to ensure the accurate interface of components based on their respective requirements. Commercially available DRTS have dedicated interface cards that allow the physical and logical connection between power systems and the hardware devices that need to be tested. This scientific approach of testing devices under dynamic conditions is termed HIL, with most events occurring in real-time.

Controller-Hardware-In-the-Loop (CHIL): With CHIL controllers used for power and energy systems applications can be connected based on communication signals, analog or digital. The dynamic conditions simulated by DRTS allow the testing of controllers connected as CHIL [68].In this project the MGMS and a SEL 700GT+ relay were connected as CHIL to the DRTS. The MGMS was the main focus of our testing and de-risking the functionalities under real-world conditions. All the technical functionalities of the MGMS were tested in a real-time environment with its metrics and conditions elaborated. For the relay, different operating scenarios were tested and iterated relay test settings several times to determine the optimum settings with the SERC team.

Real-world dynamic conditions can be imposed on the devices so as to gauge their performance prior to field deployment. The CHIL technique used for this project and the de-risking of controller functionalities in real-time is called 'Rapid Prototyping of Controller'. This is an iterative technique to rapidly transition from the first version of a controller to the final state where it is deployable. This is an intense iterative technique that requires the testing and 
development team, in this case INL, Siemens and SERC, to work at a rapid pace to achieve the final objective.

Power-Hardware-In-the-Loop (PHIL): PHIL involves the real-time simulation environment exchanging power with real, physical power hardware, such as governors, generators, renewable energy devices, electric vehicles, batteries, motors and loads [8-10]. In this project SMA PV inverter along with PV panels was used as a PHIL using a Chroma grid emulator. Different scenarios of how the system would respond based on the availability of the PV were tested.

Note that the DRTS system with HIL that was utilized at INL was configured, to the best degree possible, to accurately simulate the actual BLR microgrid system. However, there were simplifications and approximations that had to be made to configure the real time environment. For example, a standard battery model was used to approximately represent and simulate the behavior of the Tesla battery energy storage system (BESS). Due to simplifications and approximations made, some of the test configurations and/or procedures differed slightly from the characteristics of the actual system at BLR. Nonetheless, it was taken care to not to deviate significantly and the testing that was performed was extremely valuable in helping to identify and rectify control and communication issues as evidenced by the feedback received by SERC and BLR. The testing effort at INL significantly reduced the level of risk that was experienced when the actual system was deployed at the Blue Lake Rancheria.

The test procedures that are described in this document reflect the testing that was performed at INL. 


\section{Real-time Environment for BLR MGMS Testing}

\subsection{Test Plan}

Following is the brief summary of the test plan that was performed by INL for the de-risking of the MGMS developed by Siemens.

- Interface development: The RTDS ${ }^{\circledR}$ was interfaced with,

a) MGMS using Distributed Network Protocol (DNP3.0) in order to present the MGMS with signals and responses from the simulated environment.

b) PV array as a Distributed Energy Resource (DER) through SMA inverter using analog connection.

c) SEL 700GT+ relay as a intertie overcurrent protection relay using analog connections.

- BLRMG modeling in the RTDS ${ }^{\circledR}$ : A digital blueprint of the BLRMG was implemented in the RTDS $^{\circledR}$ by using both the default library of electrical components and user-defined components. - Unit testing: The unit testing of the MGMS was performed using a simulated environment based on test systems. This task was a test for the individual functionalities that were being developed in the MGMS. Typically unit testing is performed iteratively during controller development with an active feedback to the developers.

- Controller-Hardware-in-the-Loop testing for novel controller topologies: An important outcome of the unit testing was the interpretation of controller interactions between the MGMS and the smart controllers of other DERs. Testing of the smart controllers was a de-risking process that facilitated the inclusion of distributed resources in the microgrid design.

- Functionality testing using RTDS $^{\circledR}$ : The functionality testing of the MGMS was a rigorous set of tests to assess the functionalities of the controller. These tests (for both islanded and grid connected modes) were primarily based on the IEEE 1547 and CPUC Rule 21. An example simulation scenario to be tested includes the following string of events:

1) There is an interruption of power supply due to faults at PG\&E grid, 2) The voltage drops to zero and MGMS sends a command to $\operatorname{RTDS}^{\circledR}$ to island the BLRMG, 3) MGMS sends a command to start the diesel generator, 4) Once the PG\&E grid is back working, the MGMS waits for 15 minutes to verify if the PG\&E grid voltage is stable, 5) If the PG\&E grid voltage is stable the MGMS sends a command to RTDS to switch BLRMG back to PG\&E grid connected mode.

- Operator training: An operator training environment based on the real-time simulation and HIL approach was created and delivered. Training material and actual training was in close collaboration with the SERC and Siemens team. 
- Commissioning Tests: Support was provided to the SERC and Siemens teams once the MGMS was deployed at BLR to help troubleshoot unexpected and unforeseen issues.

\subsection{Components}

BLRMG: In this project, a power system network is modeled reflecting the actual system at BLR along with the different assets such as PV, battery, loads, cables, disconnects, etc. RTDS ${ }^{\circledR}$ houses the power system model consisting of PG\&E grid, $1 \mathrm{MW}$ diesel generator, battery model, transmission line, distribution network cables, transformers, circuit breakers, casino load, office load and hotel load. All the power system components are modeled based on the actual ratings of the components as provided by the SERC and BLR team. The BLRMG test set up is shown in Figure 3 below,

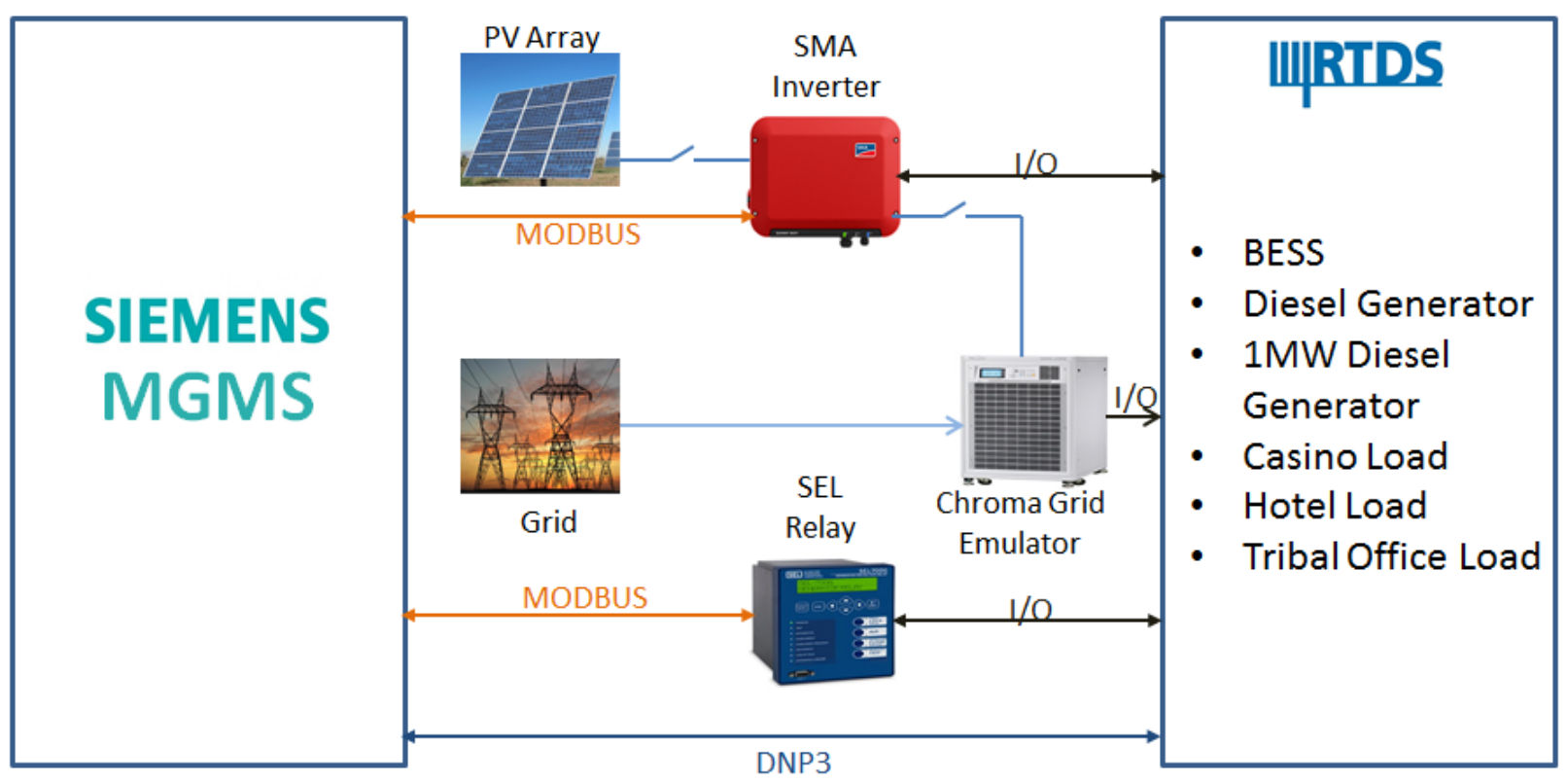

Figure 3 -BLRMG Test setup at the Power and Energy Real-time Laboratory, INL

Distributed Energy Resources: In the event of loss of power supply to the BLRMG, different DERs are used to meet the load. The different renewable and nonrenewable DERs are listed in below Table 1. $14 \mathrm{PV}$ inverters of $30 \mathrm{~kW}$ each are deployed at BLR site, one of which was connected at INL as PHIL and rest are approximated. 
Table 1 - DERs

\begin{tabular}{|c|c|}
\hline Source & Rating \\
\hline BESS & $500 \mathrm{~kW} / 1 \mathrm{MWh}$ \\
\hline Diesel generator & $1000 \mathrm{~kW}$ \\
\hline PV & $30 \mathrm{~kW} * 14=420 \mathrm{~kW}$ \\
\hline
\end{tabular}

SMA inverter: This is connected to the solar PV array at INL with suitable DC power rating and converts the DC voltage obtained from the PV to AC voltage. The SMA inverter is connected as a PHIL to the RTDS $^{\circledR}$ with a Chroma emulator as the amplifier. It helps in mimicking real-world events in the power grid. This results in the RTDS ${ }^{\circledR}$ receiving real-time voltages from the PV as analog signals and at required levels. The SMA inverter also interacts with the MGMS using MODBUS communication, which has a time delay of few milliseconds.

SEL 700GT + Relay: This is an intertie overcurrent protection relay with the primary function of control logic used for connecting/disconnecting the BLRMG with the PG\&E grid [11-13]. Additionally, when the MGMS fails, this relay takes over the control and operates the BLRMG as the backup protection. The SEL 700GT+ relay acts as CHIL to the RTDS ${ }^{\circledR}$ and communicates using analog and digital channels. It communicates with the Siemens' MGMS using MODBUS. The relay internally uses latch bit mechanism to control the breakers. Since, the relay operations are in the range of milliseconds, if a pulse to change the breaker status is sent, there is every chance of the relay missing it, if not for the latch bit (LT) mechanism. Whenever a pulse which represents the new breaker status is sent, the LT latches onto that value and retains the value until a new value is sent. Example, in the configuration used at INL, LT07 for the SEL 700GT+ is assigned to PCC circuit breaker which is used to control it.

Siemens MGMS: $\operatorname{RTDS}^{\circledR}$ communicates with the Siemens MGMS using DNP3 communication, which has a time delay of around 2 milliseconds on an average.

Tesla BESS: A generic BESS model is simulated in the RTDS ${ }^{\circledR}$ with the following three different operating modes based on the island.control status parameter. These modes were derived directly from the Tesla battery manual.

- Island.control = 1:Auto active mode, where the BESS will operate in PQ grid following mode if the grid is present, and will automatically go into VF grid forming mode if the grid is lost. When in VF mode the BESS can form the grid or it can follow and share the load with the diesel generator based on droop control commands from the MGMS. 
- Island.control = 2: PQ mode which means the grid following mode wherein the BESS will respond to power charge and discharge commands and will follow the voltage and frequency values provided by the grid. If the grid is lost the BESS will go into standby.

- Island.control = 3: The BESS will command the islanding breaker (SEL 700GT+ relay) to open and will form the islanded grid in VF mode. BESS will try to maintain a frequency of $60 \mathrm{~Hz}$ if it is the grid-forming source or it will respond to droop control commands from the MGMS in order to share the load with the diesel generator if the diesel generator is forming the islanded grid.

Loads: The different loads that are present onsite are modeled in $\operatorname{RTDS}^{\circledR}$ and the list is shown in Table 2 below. The actual load values used for modeling and nameplate load values that can be seen onsite. Loads were varied as per need for sweeping through typical load variations.

Table 2- List of loads

\begin{tabular}{|c|c|c|}
\hline Load & ${\text { Rating in } \text { RTDS }^{\circledR}(\mathbf{M W})}$ & Nameplate Rating (MVA) \\
\hline Tribal Office & 0.012 & 0.075 \\
\hline Hotel & 0.65 & 1.0 \\
\hline Casino & 0.143 & 1.0 \\
\hline Air Conditioning (AC) & 0.140 & 0.6 \\
\hline
\end{tabular}

As shown in Table 3 the AC load consists of three components. At the BLR site, there are approximately 35 individual AC package units (electric AC, natural gas heat) that make up the AC load. Numerous supply fans and exhaust fans make up the ventilation load. The AC units cycle as needed to maintain desired set point temperatures and therefore are not often all running simultaneously.

Table 3 - AC load components

\begin{tabular}{|c|c|c|}
\hline AC Load Component & Rating in $\mathbf{R T D S}^{\circledR}(\mathbf{k W})$ & Nameplate Rating (kVA) \\
\hline 3-phase motor compressors & 100 & 450 \\
\hline $\begin{array}{c}\text { Ventilation fans - Three } \\
\text { phase }\end{array}$ & 76 & 150 \\
\hline $\begin{array}{c}\text { Ventilation fans - Single } \\
\text { phase }\end{array}$ & 40 & 30 \\
\hline
\end{tabular}


Some loads at BLR were designated as controllable loads that could be shed if needed to balance onsite loads with onsite generation capacity during islanded conditions. Non-critical AC loads were designated as controllable and could be shed in a rotating manner or all at once. The noncritical AC units were divided into five groupings of approximately $37 \mathrm{~kW}$ (estimated average load) each. Rotating loads were controlled such that at any given time one load is turned OFF and all others are turned ON. The table below summarizes the AC loads and the timings associated with them.

Table 4 - AC load rotation results

\begin{tabular}{|c|c|c|c|c|c|c|c|}
\hline $\begin{array}{l}\text { Load } \\
\text { name }\end{array}$ & $\begin{array}{l}\text { Load } \\
\text { status at } \\
t=0\end{array}$ & $\begin{array}{l}\text { Load } \\
\text { status at } \\
t=1\end{array}$ & $\begin{array}{l}\text { Load } \\
\text { status at } \\
\mathrm{t}=2\end{array}$ & $\begin{array}{l}\text { Load } \\
\text { status at } \\
t=3\end{array}$ & $\begin{array}{l}\text { Load } \\
\text { status at } \\
t=4\end{array}$ & $\begin{array}{l}\text { Load } \\
\text { status at } \\
t=5\end{array}$ & $\begin{array}{l}\text { Load (in } \\
\mathbf{k W} \text { ) }\end{array}$ \\
\hline Load 1 & $\mathrm{ON}$ & ON & $\mathrm{ON}$ & $\mathrm{ON}$ & OFF & $\mathrm{ON}$ & 37 \\
\hline Load 2 & $\mathrm{ON}$ & $\mathrm{ON}$ & $\mathrm{ON}$ & OFF & $\mathrm{ON}$ & $\mathrm{ON}$ & 37 \\
\hline Load 3 & $\mathrm{ON}$ & $\mathrm{ON}$ & OFF & $\mathrm{ON}$ & $\mathrm{ON}$ & $\mathrm{ON}$ & 37 \\
\hline Load 4 & $\mathrm{ON}$ & OFF & $\mathrm{ON}$ & $\mathrm{ON}$ & ON & $\mathrm{ON}$ & 37 \\
\hline Load 5 & OFF & $\mathrm{ON}$ & $\mathrm{ON}$ & $\mathrm{ON}$ & $\mathrm{ON}$ & OFF & 37 \\
\hline $\begin{array}{l}\text { Total } \\
\text { Load } \\
(\mathrm{kW})\end{array}$ & 148 & 148 & 148 & 148 & 148 & 148 & \\
\hline
\end{tabular}

\subsection{Assumptions}

- Tesla battery was not available for hardware HIL during testing so its behavior was emulated in $\operatorname{RTDS}^{\circledR}$ as per the specifications using a model-based approach.

- The transient behavior of the Tesla battery cannot be modeled exactly as that of the actual battery deployment due to lack of sufficient information. Due to these assumptions, the transient and dynamic simulation results of the battery may not reflect the actual results seen onsite.

- The relay associated with BESS was not included and the switching operation of different modes of the battery based on the relay action was assumed to be perfect.

- We have used only one SMA inverter as PHIL, and with RTDS ${ }^{\circledR}$ capability, we simulated the system emulating 14 inverters based on the actual performance and real-time characterization of the one SMA inverter.

- The communications in the field and the hardware devices in the BLRMG are always assumed to be working normally with no failures. 
The Single Line diagram of BLRMG power system model is shown in Figure 4 below.

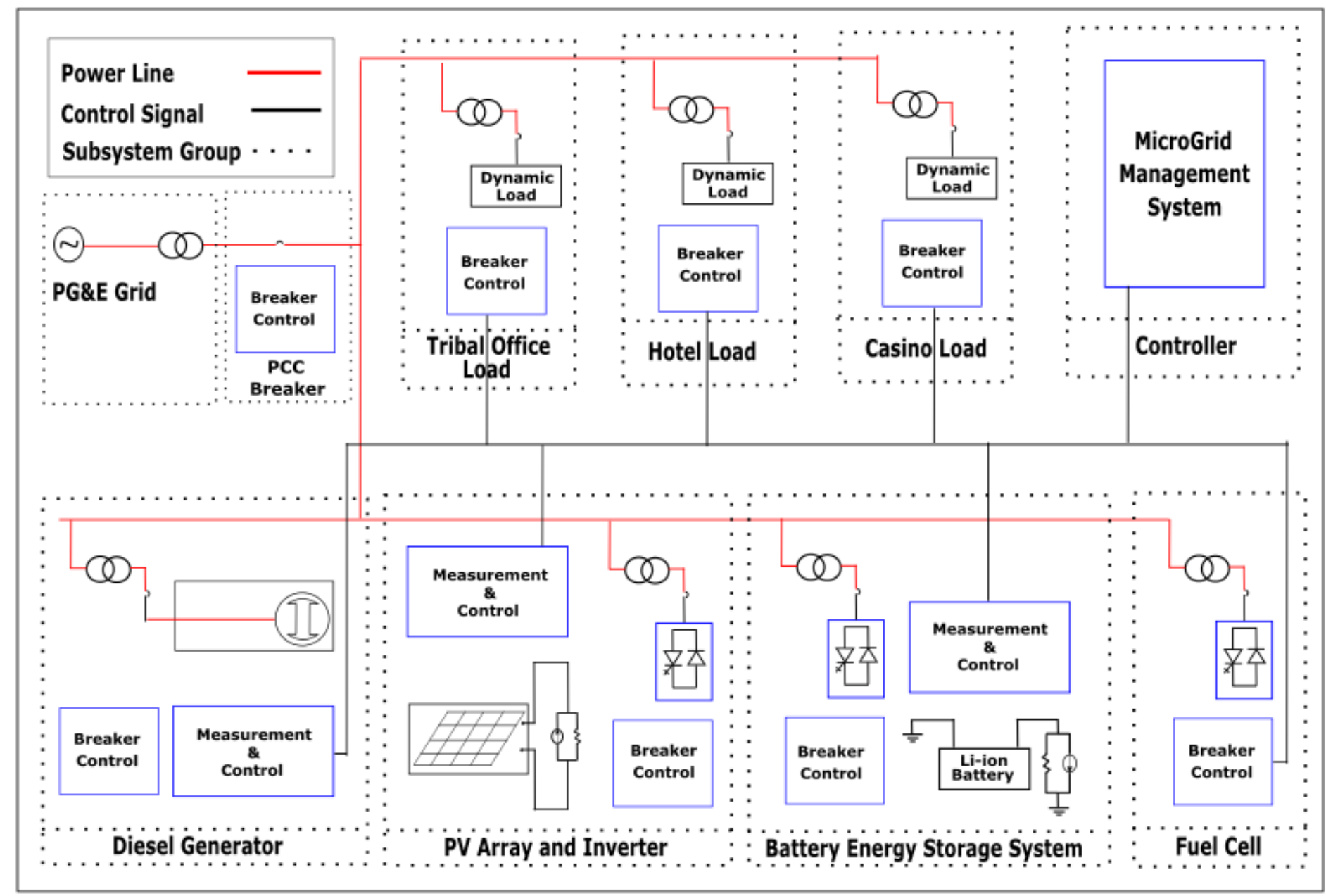

Figure 4 - Single line diagram of BLR power system model in $\operatorname{RTDS}^{\circledR}$ 


\section{Test Procedures for MGMS Unit and Functionality Testing}

The MGMS functionality is built using different Sequence of Event (SOE) functions. SOE is a set of steps which has to be performed based on the prevailing conditions of the system. These steps need to be performed in real-time, and for this reason certain SOE functions are automated and do not require operator intervention. Certain SOE functions are manual and will not be triggered automatically and were primarily built for unit testing and operator training. So, for every possible transition scenario there will be an associated SOE that can run automatically or manually. For automated SOEs, if current system conditions meet the requirements of a particular SOE, then the MGMS should run that particular SOE. BLR system conditions acquired as measurements in real-time and via communications are used as triggers for SOE. Ideally, the MGMS keeps operating within these predefined SOEs and are chosen based on the system conditions. At any time, only one SOE is executed by the MGMS to operate the BLRMG. There is an SOE designed for all operational modes foreseen in the future considering the given configurations in the BLRMG as described earlier. All the SOEs underwent both unit and functionality testing with real-time environment, CHIL and PHIL setup. Below, are some of the SOEs explained in detail. The description of SOE is provided, when it should run, what the initial conditions are, and what the desired output is. The SOE is said to be successful if the final system conditions are same as the desired output. For the unit testing the each SOE was successfully analyzed individually, whereas the functionality testing included the SOEs operating in sequences as desired to consider all operating conditions of the BLRMG.

\section{A. Black start with diesel generator:}

Description: This SOE will be used when there is an interruption of supply from the PG\&E grid due to faults and the battery is not capable of supporting the load without the diesel generator. It was to be verified whether or not the MGMS turns ON the diesel generator when no other DER is available and thereby providing power to the electric loads.

Scenario: In this test, initially, the BLRMG is in grid connected mode, and battery is in grid following mode. The following steps are observed when the PG\&E grid voltage is reduced to zero, mimicking a fault to test the functionality:

1) The SEL 700GT+ relay will open the PCC CB

2) The MGMS will immediately start the diesel generator

3) After a delay of 5 seconds, when the diesel generator voltage is within $95 \%$ of nominal, the ATS1 breaker is closed to have the BLRMG in islanded mode with diesel generator as the only source.

Observed Result: All the steps were executed as required and the diesel generator was able to meet all the load demands which include hotel, tribal office, and casino. 


\section{B. Black start with BESS:}

Description: This SOE will be used when there is an interruption of supply from the PG\&E grid due to faults and the BESS is capable of meeting the load by itself. It was to be verified if the MGMS turns ON the BESS and meets the onsite load.

Scenario: In this test, initially, the BLRMG is in grid connected mode, and BESS is in grid following mode. The following steps are observed when PG\&E Grid voltage is reduced to zero, mimicking a fault to test the functionality:

1) The SEL 700GT+ relay will open the PCCCB.

2) The MGMS will change the island control from 2 to 3, thereby changing the BESS from grid following to grid forming mode

Observed Result: All the steps were executed as expected and the BESS was able to meet the load demands up to $500 \mathrm{~kW}$ as modeled in the BLRMG.

\section{Black Start with BESS and diesel generator:}

Description: This SOE will be used when there is an interruption of supply from the PG\&E grid due to faults. We verify if the MGMS turns ON both the diesel generator and BESS with no other source available and thereby keeping the BLRMG running.

Scenario: In this test the BLRMG is initially in grid connected mode and the battery is in grid following mode. The following steps are observed when the PG\&E grid voltage is reduced to zero to test the functionality:

1) The SEL 700GT+ relay will open the PCCCB

2) The MGMS will immediately start the diesel generator

3) After a delay of 5 seconds, when the diesel generator voltage is within $95 \%$ of nominal, the ATS1 breaker is closed to have the BLRMG in islanded mode with diesel generator as the only source.

4) The MGMS will change the island.control parameter from 2 to 3 , thereby changing the battery from PG\&E grid following to grid forming mode. The frequency droop control setting will be used to control how much of the load the BESS shares with the diesel generator.

Observed Result: All the steps were executed as required and both the diesel generator and BESS were turned ON and were able to meet the load demands from the hotel, tribal office and casino.

\section{Manual Reconnection to PG\&E grid when islanded with diesel generator:}

Description: This SOE will be used when we have the PG\&E grid back after a PG\&E grid failure and the BLRMG is running in islanded mode with only the diesel generator meeting the load. This SOE will work only after the PG\&E grid is back and the voltage and frequency is stable for 15 minutes as observed and measured at PCC.

Scenario: In this test, the BLRMG is initially in islanded mode with only the diesel generator providing power. The following steps are performed/observed in this test: 
1) The PG\&E grid voltage is brought back with a stable voltage and frequency for 15 minutes

2) Wait for 65 seconds as the SEL 700GT+ relay will wait for PG\&E grid to be back online for 60 seconds before it can be operated to close the PCC breaker.

3) ATS1 breaker is opened

4) PCC breaker is closed

5) After 5 seconds, the diesel generator is turned off.

Observed Result: All the steps were executed as required and BLRMG is in grid connected mode with PG\&E grid able to meet the load and diesel generator was turned off.

\section{E. Manual Reconnection to PG\&E grid when islanded with BESS:}

Description: This SOE will be used when we have the PG\&E grid back after a PG\&E grid failure and the BLRMG is running in islanded mode with only the BESS meeting the load. This SOE will work only after the PG\&E grid is back and the voltage and frequency is stable for 15 minutes.

Scenario: In this test, the BLRMG is initially in islanded mode with only the BESS as a generator. The following steps are performed/observed in this test:

1) The PG\&E grid voltage is brought back and voltage and frequency was stable for 15 minutes

2) Wait for 65 seconds as the SEL 700GT+ relay will wait for PG\&E grid to be back online for 60 seconds before it can be operated to close the PCC breaker.

3) The MGMS will change the island.control parameter to 2 , thereby changing the battery from grid forming to standby mode.

4) When the microgrid bus is de-energized the PCC breaker is closed.

Observed Result: All the steps were executed as required and BLRMG is in grid-connected mode with PG\&E grid able to meet the load and BESS in standby mode. 


\section{Test Procedures - Secondary Protection without MGMS}

The SEL 700GT+ relay is used as a second layer of protection if the MGMS were to fail for any reason. This ensures that the BLRMG will run even in the absence / malfunction of the MGMS, thereby providing a failsafe environment. The SEL 700GT+ relay gets the verifications through a continuous heartbeat from MGMS. These protection mechanisms safeguard against MGMS failures from both hardware and logic perspective. The logic was primarily developed by SERC personnel with an iterative feedback from INL.

This section describes the testing of SEL700GT+ configurations for the BLRMG project using DRTS. The SEL 700GT+ relay was programmed using AcSELerator ${ }^{\circledR}$ to provide a base level of automation to ensure safe and reliable operation of the BLRMG with or without the responsiveness of the Siemens' MGMS in operation. Several scenarios were tested representing different operating conditions of concern. This section focuses on cases where the MGMS is unresponsive and the SEL 700GT+ relay provides the necessary logic and controls to operate the BLR system. The trigger to operate BLRMG programmed within the SEL 700GT+ are expected to be automatic based on a continuous heartbeat it receives from the MGMS. There are a few instances when it is possible for a manual intervention and enable asset controls using the SEL 700GT+, especially for conditions related to operations and maintenance.

\section{Scenario 1: Automatic transition to islanded operations with MGMS unresponsive}

This scenario served to check the ability of the SEL 700GT+ relay to establish a diesel generator based islanded BLRMG when the PG\&E grid goes offline and the MGMS fails to establish an islanded BLRMG within 15 seconds.

\section{Test Condition Sequence}

The following conditions are simulated to test this functionality:

1) The BLRMG is grid-connected and a loss of PG\&E grid is experienced.

2) The MGMS fails to black start the islanded BLRMG within 15 seconds

\section{Observed Results}

Table 5 - Test results for transition to islanded operations after MGMS non-response

\begin{tabular}{|c|l|l|}
\hline Actor & \multicolumn{1}{|c|}{ Expected Action } & Result \\
\hline SEL700GT+ & $\begin{array}{l}\text { SEL700GT+ sets LT07 to FALSE after 15 seconds of de-energized } \\
\text { islanded status. Start signal sent to ATS1. }\end{array}$ & Pass \\
\hline $\begin{array}{c}\text { Diesel } \\
\text { generator }\end{array}$ & Diesel generator should start & Pass \\
\hline ATS1 & ATS1 should transfer diesel generator to the islanded BLRMG. & Pass \\
\hline
\end{tabular}


With these test results from Table 5, we confirmed that if the PG\&E grid fails and the MGMS does not respond appropriately, the SEL700GT+ relay will kick in and start the diesel generator thereby maintaining a stable BLRMG.

\section{Scenario 2: Automatic Transfer to diesel generator during MGMS downtime}

This scenario served to check the ability of the SEL 700GT+ relay to establish a diesel generator based islanded BLRMG when the PG\&E GRID goes offline and the MGMS is offline.

Test Condition Sequence

1) MGMS is offline (LT07 FALSE)

2) The BLRMG is grid-connected and a loss of PG\&E grid is experienced.

\section{Observed Results}

Table 6 - Test results for transition to islanded operations with MGMS offline

\begin{tabular}{|c|l|l|}
\hline Actor & \multicolumn{1}{|c|}{ Expected Action } & Result \\
\hline SEL700GT+ & $\begin{array}{l}\text { PCC-CB is opened } \\
\text { Start signal is sent to diesel generator immediately } \\
\text { Start signal sent to ATS1 when diesel generator voltage is }>95 \% \\
\text { nominal }\end{array}$ & Pass \\
\hline Diesel generator & Diesel generator should start. & Pass \\
\hline ATS1 & ATS1 should transfer diesel generator to the islanded BLRMG. & Pass \\
\hline
\end{tabular}

With these test results from Table 6, we confirmed that if the PG\&E grid fails and MGMS is offline, the relay will start the diesel generator and close its tie breaker thereby maintaining a stable BLRMG.

\section{Scenario 3: Auto-Reconnect to PG\&E grid during MGMS downtime}

This scenario served to check the relay's ability to re-establish PG\&E grid connection when the PG\&E grid is re-energized during islanded operations and the MGMS is offline.

It should follow from Scenario 2.

\section{Test Condition Sequence}

1) MGMS is offline (LT07 FALSE)

2) Simulate islanded operations formed by diesel generator without BESS or PV support.

3) PG\&E grid transitions from de-energized to energized

\section{Observed Results}

Two cases were tested: successful reconnection and delayed reconnection due to PG\&E grid instability. 


\section{Case 1: Successful reconnection to the PG\&E grid}

Table 7 - Test results for successful reconnection after 15 minutes of PG\&E grid stability

\begin{tabular}{|c|l|l|}
\hline Actor & \multicolumn{1}{|c|}{ Expected Action } & Result \\
\hline SEL700GT+ & $\begin{array}{l}\text { Relay waits 15 minutes while the PG\&E grid is continuously within specification } \\
\text { and then sends a command to disconnect diesel generator and reconnect the PCC- } \\
\text { CB }\end{array}$ & Pass \\
\hline ATS1 & Disconnects diesel generator, the BLRMG experiences black-out. & Pass \\
\hline $\begin{array}{c}\text { Diesel } \\
\text { generator }\end{array}$ & Diesel generator goes into cool down cycle and is powered down & Pass \\
\hline PCC-CB & PCC-CB is closed upon ATS1 disconnect and the BLRMG is restored & Pass \\
\hline
\end{tabular}

With these test results from Table 7, we confirmed that if the PG\&E grid comes back online after a PG\&E grid failure and stays stable for 15 minutes and the MGMS is offline, the relay will return the BLRMG in grid-connected state and turn off the diesel generator.

\section{Case 2: Delayed reconnection to the $P G \& E$ grid}

Table 8 - Test results for interrupted reconnection

\begin{tabular}{|c|l|l|}
\hline Actor & \multicolumn{1}{|c|}{ Expected Action } & Result \\
\hline SEL700GT+ & $\begin{array}{l}\text { Relay waits 15 minutes while the PG\&E grid is within specification, } \\
\text { instabilities in the PG\&E grid result in a resetting of the 15 minute timer. } \\
\text { Following a reset timer, 15 minutes of stable PG\&E grid operations } \\
\text { triggers the remainder of the sequence. }\end{array}$ & Pass \\
\hline ATS1 & Disconnects diesel generator, the BLRMG experiences black-out. & Pass \\
\hline $\begin{array}{c}\text { Diesel } \\
\text { generator }\end{array}$ & $\begin{array}{l}\text { Diesel generator start signal is de-asserted and generator enters cool } \\
\text { down cycle and is powered down }\end{array}$ & Pass \\
\hline PCC-CB & $\begin{array}{l}\text { PCC-CB is closed upon ATS1 disconnect and the BLRMG is restored to } \\
\text { PG\&E grid operations. }\end{array}$ & Pass \\
\hline
\end{tabular}

With these test results from Table 8, we confirmed that if the PG\&E grid comes back online after a PG\&E grid failure and does not stay stable for 15 minutes and MGMS is offline, the relay will maintain the BLRMG in islanded mode until the PG\&E grid is back online and stable for 15 consecutive minutes.

\section{Scenario 4: Manual disconnect from PG\&E grid through relay with Unresponsive MGMS}


This scenario served to test the ability of the relay to facilitate a manual disconnect from the PG\&E grid upon operator input.

\section{Test Condition Sequence}

1. Simulate grid connected operations (PG\&E grid is operational)

2. MGMS is offline (LT07 FALSE)

3. Operator Holds TRIP button for 0.25 seconds while the Tie breaker is selected and Lock is disabled.

Observed Results

Table 9 - Test results for manual disconnect from $P G \& E$ grid due to relay button press

\begin{tabular}{|c|l|l|}
\hline Actor & \multicolumn{1}{|c|}{ Expected Action } & Result \\
\hline SEL700GT+ & $\begin{array}{l}\text { Upon operator pressing the trip push-button, the tie-breaker trip light } \\
\text { should flash for 15 seconds before opening the PCC-CB. } \\
\text { After breaker opens, T04_LED (labeled "VOLTS/HERTZ") should light }\end{array}$ & Pass \\
\hline PCC-CB & $\begin{array}{l}\text { The SEL700GT+ commands the PCC-CB to open after the 15 second } \\
\text { wait time. }\end{array}$ & Pass \\
\hline $\begin{array}{c}\text { Diesel } \\
\text { generator }\end{array}$ & Diesel generator starts immediately when button is pressed & Pass \\
\hline ATS1 & $\begin{array}{l}\text { Upon PCC-CB opening, the relay should command ATS1 to transfer to } \\
\text { diesel generator since diesel generator voltage will have reached 95\% by } \\
\text { the time the 15 second delay time expires. }\end{array}$ & Pass \\
\hline
\end{tabular}

With these test results from Table 9, we confirmed that with BLRMG in grid-connected mode and the MGMS offline, if the operator manually trips the PCC breaker, the relay will turn ON the diesel generator and the BLRMG will go into islanded mode.

\section{Scenario 5: Verification of PCC-CB Lock-out}

Following the manual disconnect from the PG\&E grid described in Scenario 4, no action should be able to close the PCC-CB (PCC-CB) except for the operator using the close push button on the SEL700GT+. This is a safety measure in case the $12 \mathrm{kV}$ system requires maintenance.

\section{Test Conditions}

1. Implement a manual disconnect from the PG\&E grid

2. Attempt to close the PCC-CB using the Tesla SMC status(Island.control $=1$ or Island. Control = 2)

3. Attempt to close the PCC-CB using the MGMS

4. Attempt to close the PCC-CB by using the SEL700GT+ CLOSE push button 


\section{Observed Results}

There are three cases to test under scenario 5 as described in the test conditions above. Attempts to close the breaker by the Tesla SMC or MGMS should not be successful. Only the SEL700GT+ push button should be able to successfully close the breaker.

Case 1: Closing the PCC-CB by the Tesla SMC

Table 10-Close PCC-CB attempt by Tesla SMC

\begin{tabular}{|c|l|l|}
\hline \multicolumn{1}{|c|}{ Actor } & Expected Action & Result \\
\hline TESLA SMC & $\begin{array}{l}\text { Island.Control = 1 or } \\
\text { Island.Control = } 2\end{array}$ & Pass \\
\hline SEL700GT+ & No Action & Pass \\
\hline
\end{tabular}

With these test results from Table 10, we confirmed that after the operator has manually tripped the PCC breaker and the BLRMG in islanded mode, the TESLA SMC cannot force the BLRMG to go to grid-connected mode.

\section{Case 2: Closing the PCC-CB by the MGMS}

Table 11-Close PCC-CB attempt by MGMS

\begin{tabular}{|c|l|l|}
\hline Actor & Expected Action & Result \\
\hline MGMS & BO_00 = close & Pass \\
\hline SEL700GT+ & No Action & Pass \\
\hline
\end{tabular}

With these test results from Table 11, we confirmed that after the operator has manually tripped the PCC breaker and the BLRMG is in islanded mode, the MGMS cannot force the BLRMG to go to grid-connected mode.

Case 3: Closing the PCC-CB by the SEL 700GT+

Table 12 - Close attempt by operator using SEL700GT+ close push button

\begin{tabular}{|c|l|c|}
\hline Actor & \multicolumn{1}{|c|}{ Expected Action } & Result \\
\hline SEL700GT+ & $\begin{array}{l}\text { Upon operator pressing the CLOSE push-button, the tie-breaker close } \\
\text { light should flash for 15 seconds before disconnecting diesel generator } \\
\text { and closing the PCC-CB. }\end{array}$ & Pass \\
\hline
\end{tabular}


With these test results from Table 12, we confirmed that after the operator has manually tripped the PCC breaker and the BLRMG in islanded mode, only a manual operation by the operator on the relay can get the BLRMG to go to grid-connected mode.

\section{Scenario 6: Manual disconnect of diesel generator during MGMS downtime}

This scenario served to test the ability of the relay to facilitate a temporary manual disconnect from diesel generator upon operator input with BLRMG in islanded mode.

\section{Test Conditions}

1) MGMS is offline (LT07 FALSE)

2) Simulate islanded operations in $\operatorname{RTDS}^{\circledR}$ formed by diesel generator without BESS or PV support.

3) Operator Holds TRIP button for 0.25 seconds while the Gen breaker is selected and Lock is disabled.

\section{Observed Results}

Table 13 - Disconnect of diesel generator using pushbutton while islanded

\begin{tabular}{|c|l|c|}
\hline Actor & \multicolumn{1}{|c|}{ Expected Action } & Result \\
\hline SEL700GT+ & $\begin{array}{l}\text { Upon operator pressing the TRIP push-button, ATS1 should immediately } \\
\text { be disconnected. } \\
\text { 60s later, if PG\&E grid is not available, ATS1 should be reconnected }\end{array}$ & Pass \\
\hline ATS1 & $\begin{array}{l}\text { Opens immediately after button press } \\
\text { Closes 60s later }\end{array}$ & Pass \\
\hline
\end{tabular}

With these test results from Table 13, we confirmed that when the BLRMG is in islanded mode and the operator tries to open the ATS1 breaker, the breaker opens and, with the PG\&E grid still not online, the breaker recloses in 60 seconds.

\section{Scenario 7: Manual start of diesel generator while on PG\&E grid}

This scenario served to test the ability of the relay to start diesel generator upon operator input.

\section{Test Condition Sequence}

1) The BLRMG is grid-connected.

2) LT07 is false

3) Operator Holds CLOSE button for 0.25 seconds while the Gen breaker is selected and Lock is disabled. 


\section{Observed Results}

Table 14 - Disconnect of diesel generator using pushbutton while islanded

\begin{tabular}{|c|l|c|}
\hline Actor & \multicolumn{1}{|c|}{ Expected Action } & Result \\
\hline SEL700GT+ & $\begin{array}{l}\text { Upon operator pressing the CLOSE push-button, diesel generator should } \\
\text { start (LT14 = TRUE) } \\
5 \text { minutes later, diesel generator should stop (LT14 = FALSE) }\end{array}$ & 'Pass \\
\hline $\begin{array}{c}\text { Diesel } \\
\text { generator }\end{array}$ & $\begin{array}{l}\text { Starts immediately } \\
\text { Stops 5 minutes later }\end{array}$ & Pass \\
\hline
\end{tabular}

With these test results from Table 14, we confirmed that with the BLRMG in grid-connected mode and when operator manually starts the diesel generator on the relay, the diesel generator will start but the relay will turn it off after 5 minutes as there is no need of diesel generator when BLRMG is in grid-connected mode.

\section{Scenario 8: Manual stop of diesel generator while on PG\&E grid}

This scenario served to test the ability of the relay to stop diesel generator upon operator input after it has been manually started.

\section{Test Condition Sequence}

1) The BLRMG is grid-connected.

2) Operator Holds CLOSE button for 0.25 seconds while the Gen breaker is selected and Lock is disabled.

3) Operator Holds TRIP button for 0.25 seconds while the Gen breaker is selected and Lock is disabled.

\section{Observed Results}

Table 15 - Disconnect of diesel generator using pushbutton while islanded

\begin{tabular}{|c|l|c|}
\hline Actor & \multicolumn{1}{|c|}{ Expected Action } & Result \\
\hline SEL700GT+ & $\begin{array}{l}\text { Upon operator pressing the CLOSE push-button, diesel generator should } \\
\text { start (LT14 = TRUE) } \\
\text { Upon operator pressing the TRIP push-button, diesel generator should } \\
\text { stop (LT14 = FALSE) }\end{array}$ & Pass \\
\hline $\begin{array}{c}\text { Diesel } \\
\text { generator }\end{array}$ & $\begin{array}{l}\text { Starts when CLOSE pressed } \\
\text { Stops when TRIP pressed }\end{array}$ & Pass \\
\hline ATS1 & No action & Pass \\
\hline
\end{tabular}


With these test results from Table 15, we confirmed that with the BLRMG in grid-connected mode, the diesel generator turned $\mathrm{ON}$ by the operator, and the operator tries to manually stop the diesel generator through the relay, the diesel generator will turn off.

\section{Scenario 9: Verification of button functions and indicator lights}

This scenario served to test the ability of various push-buttons on the relay to change modes as expected.

\section{Test Sequence}

1) Press and hold SELECT button for $0.25 \mathrm{~s}$

2) Select should toggle between Tie and Gen

3) Press LOCK button for $3 \mathrm{~s}$

4) Lock state should toggle between Enabled and Disabled

5) Set LOCK to Enabled

6) Select Tie breaker and press TRIP

7) Nothing should happen

8) Press and hold SELECT and LOCK simultaneously for $5 \mathrm{~s}$

9) MGMS offline state should toggle on and off

\section{Observed Results}

The results for each button press are listed below.

Table 16 - Push-button operation

\begin{tabular}{|c|l|l|}
\hline \multicolumn{1}{|c|}{ Actor } & \multicolumn{1}{|c|}{ Expected Action } & Result \\
\hline SEL700GT+ & Pressing SELECT should cause Gen/Tie lights to toggle & Pass \\
\hline SEL700GT+ & Holding LOCK for 3s should toggle Lock state lights & Pass \\
\hline SEL700GT+ & $\begin{array}{l}\text { Pressing TRIP with Tie breaker selected and LOCK enabled should have } \\
\text { no effect }\end{array}$ & Pass \\
\hline SEL700GT+ & $\begin{array}{l}\text { Pressing and holding SELECT and LOCK simultaneously for 5s should } \\
\text { cause MGMS offline state to toggle on and off (T01_LED, labeled } \\
\text { "DIFFERENTIAL", should go on and off) }\end{array}$ & Pass \\
\hline
\end{tabular}

With these test results from Table 16, we confirmed that all the push buttons on the relay function as required. 


\section{Test Procedures for Operator Training}

\subsection{Operator Training Setup}

The operators from BLR were invited to INL so they could gain hands-on experience with the system they would be operating onsite at BLR. To achieve this, four computer workstations equipped with all the necessary software and interfaces were set up. Each operator was assigned one workstation through which they could access the RTDS ${ }^{\circledR}$, CHIL and PHIL setup. The personnel from the INL team operated the RTDS ${ }^{\circledR}$, SEL 700GT+ relay, and SMA inverter. The personnel from Humboldt State University and INL conducted the training. The personnel from Siemens helped the operators with deeper understanding of the MGMS functionality as and when required.

The training was scheduled for two days (01/18/2017- 01/19/2017) and started with a tour of the lab at INL where the hardware to be used later in the training was shown and explained. Later each BLR operator was assigned a workstation with functioning MGMS software. The overall system and functionality of the MGMS software was described to the trainees and they were given some time to interact with the software interface. Then over the two days of training many Sequence of Events (SOEs) were tested and the objective behind those SOEs was explained. Each operator was asked to perform the SOEs, and on the 2nd day they were asked to create their own SOEs based on their understanding of the system. The BLR operators were provided a controlled environment to gain experience of the BLRMG and MGMS operations. Given diverse set of conditions and to better understand SOEs, below are the operator activities that were conducted during the training.

\subsection{Training Activities}

Operator Activity 1: Expected results after PG\&E outage Scenario: The BLRMG is running in grid-connected mode and there is a PG\&E outage. The battery is not able to support the microgrid without the diesel generator and the MGMS is online. Objective: The MGMS should automatically run the SOE that commands the BLRMG to go to islanded mode from grid-connected mode and starts the diesel generator. The operator sees the below steps when the SOE starts and results are shown in Table 17.

\section{Steps:}

- MGMS should trip the PCC breaker through the relay

- MGMS should start the SOE that starts the generator

- ATS1 switch should close within 15 seconds by MGMS.

- PV goes offline and should restore in 5 minutes 
Table 17-SOE after a PG\&E outage

\begin{tabular}{|c|c|c|}
\hline Actor & Expected Action & Result \\
\hline MGMS & Island Mode & Pass \\
\hline $\begin{array}{l}\text { PG\&E } \\
\text { Grid }\end{array}$ & De-energized & Pass \\
\hline Relay & Trips breaker & Pass \\
\hline PCC-CB & Open & Pass \\
\hline PV & $\begin{array}{l}\text { Trips offline. Restores in } 5 \text { minutes after } \\
\text { island black-start }\end{array}$ & Pass \\
\hline BESS & $\begin{array}{l}\text { After ATS1 closes, goes to standby mode. } \\
\text { Unloaded. }\end{array}$ & Pass \\
\hline $\begin{array}{c}\text { Diesel } \\
\text { generator }\end{array}$ & Started by MGMS & Pass \\
\hline ATS1 & $\begin{array}{l}\text { Closes after diesel generator reaches } 95 \% \text { of } \\
\text { nominal voltage }\end{array}$ & Pass \\
\hline
\end{tabular}

Operator Activity 2: Expected results following reconnection sequence.

Scenario: The BLRMG is running in islanded mode and PG\&E grid is back online.

Objective: The MGMS should detect that that the PG\&E grid is stable for 15 minutes and then automatically run the SOE that commands the BLRMG to go to grid connected mode.

The operator sees the below steps when the SOE starts and results are shown in Table 18.

Steps:

- After 15 minutes, MGMS should start the SOE that reconnects BLRMG back to grid connected mode

- MGMS opens the ATS1 breaker

- MGMS closes the PCC breaker through the relay

- After 5 minutes, generator is turned off. 
Table 18 - SOE for reconnection of BLRMG to PG\&E grid

\begin{tabular}{|c|l|c|}
\hline Actor & \multicolumn{1}{|c|}{ Expected Action } & Description \\
\hline MGMS & $\begin{array}{l}\text { Detects PG\&E Grid Status and executes } \\
\text { reconnection sequences. Enters grid } \\
\text { connected mode. }\end{array}$ & Pass \\
\hline $\begin{array}{c}\text { PG\&E } \\
\text { Grid }\end{array}$ & Energized & Pass \\
\hline Relay & Supervises closure of PCC-CB & Pass \\
\hline PCC-CB & Closed & Pass \\
\hline PV & $\begin{array}{l}\text { Trips offline and restores 5 minutes after } \\
\text { reconnection to PG\&E grid. }\end{array}$ & Pass \\
\hline BESS & $\begin{array}{l}\text { Synchronizes and reconnects to PG\&E } \\
\text { grid, enters PQ mode, Island.Control = 2 }\end{array}$ & Pass \\
\hline $\begin{array}{c}\text { Diesel } \\
\text { generator }\end{array}$ & Offline & Pass \\
\hline ATS1 & Open & Pass \\
\hline
\end{tabular}

Operator Activity 3: Expected results following actions to turn off diesel generator. Scenario: The BLRMG is running in islanded mode and a manual SOE to turn off generator is started.

Objective: Once the operator starts the SOE in MGMS that turns off the diesel generator, battery should be able to pick up the load up to $500 \mathrm{~kW}$.

The following steps are observed when the operator starts the SOE and results are shown in Table 19

\section{Steps:}

- MGMS commands the relay to open ATS1 breaker.

- Battery should ramp to carry the entire microgrid load and will set microgrid voltage and frequency based on set points sent by MGMS. 
Table 19 - Manual SOE to turn off diesel generator

\begin{tabular}{|c|l|c|}
\hline Actor & \multicolumn{1}{|c|}{ Expected Action } & Result \\
\hline MGMS & $\begin{array}{l}\text { Sends command to SEL relay to open } \\
\text { ATS1 and stop generator }\end{array}$ & Pass \\
\hline Relay & $\begin{array}{l}\text { Commands ATS1 open and de-asserts } \\
\text { generator start signal }\end{array}$ & Pass \\
\hline PV & Stays Online & Pass \\
\hline BESS & $\begin{array}{l}\text { Grid-forming and picks up load less PV } \\
\text { generation }\end{array}$ & Pass \\
\hline $\begin{array}{c}\text { Diesel } \\
\text { generator }\end{array}$ & Offline & Pass \\
\hline ATS1 & Open & Pass \\
\hline
\end{tabular}

Operator Activity 4: Expected results following reconnection sequence.

Scenario: Operator Activity 3 is completed and the BLRMG is running in islanded mode with battery and PV providing the power. The PG\&E grid is now back online.

Objective: The MGMS should detect that the PG\&E grid is stable for 15 minutes and then automatically run the SOE that commands the BLRMG to go to grid connected mode.

The operator sees the below steps when the SOE starts and results are shown in Table 20.

Steps:

- After 15 minutes MGMS should start the SOE that reconnects BLRMG back to grid connected mode

- MGMS should command the battery to synchronize with the PG\&E grid and close the PCC breaker

- MGMS changes the battery's island control to 2, meaning battery should go to gridfollowing (PQ) mode. 
Table 20 - SOE for reconnection sequence with BLRMG islanded with BESS

\begin{tabular}{|c|l|c|}
\hline Actor & \multicolumn{1}{|c|}{ Expected Action } & Result \\
\hline MGMS & $\begin{array}{l}\text { Detects PG\&E status and executes } \\
\text { reconnection sequences. Enters grid- } \\
\text { connection mode. }\end{array}$ & Pass \\
\hline $\begin{array}{c}\text { PG\&E } \\
\text { Grid }\end{array}$ & Energized & Pass \\
\hline Relay & Supervises closure of PCC-CB & Pass \\
\hline PCC-CB & Closed & Pass \\
\hline PV & $\begin{array}{l}\text { Trips offline and restores 5 minutes after } \\
\text { reconnection to PG\&E grid. }\end{array}$ & Pass \\
\hline BESS & $\begin{array}{l}\text { Synchronizes and reconnects to PG\&E grid, } \\
\text { enters PQ mode, Island.Control =2 }\end{array}$ & Pass \\
\hline $\begin{array}{c}\text { Diesel } \\
\text { generator }\end{array}$ & Offline & Pass \\
\hline ATS1 & Open & Pass \\
\hline
\end{tabular}

Operator Activity 5: Black start with BESS

Scenario: The BLRMG is running in grid-connected mode and there is an outage on PG\&E grid. The diesel generator is unavailable and MGMS is online

Objective: The MGMS should automatically run the SOE that commands the BLRMG to go to islanded mode from grid-connected mode and BESS to grid forming mode.

The operator sees the below steps when the SOE starts and results are shown in Table 21.

\section{Steps:}

- MGMS should trip the PCC breaker through the relay

- MGMS should start the SOE that black starts the microgrid with the battery

- The MGMS sends a load shed command to the Johnson Controls energy management system, which will reduce the Casino AC loads.

- $\quad$ MGMS sends island control = 3 to battery.

- PV goes offline and should restore in 5 minutes 
Table 21 - SOE for black start with BESS

\begin{tabular}{|c|l|c|}
\hline Actor & \multicolumn{1}{|c|}{ Expected Action } & Result \\
\hline MGMS & Island Mode & Pass \\
\hline $\begin{array}{c}\text { PG\&E } \\
\text { Grid }\end{array}$ & De-energized & Pass \\
\hline Relay & Trips breaker & Pass \\
\hline PCC-CB & Open & Pass \\
\hline PV & $\begin{array}{l}\text { Trips offline. Restores in 5 minutes after } \\
\text { island black-start }\end{array}$ & Pass \\
\hline BESS & $\begin{array}{l}\text { Used to black start the BLRMG. } \\
\text { Island.Control = 3 }\end{array}$ & Pass \\
\hline $\begin{array}{c}\text { Diesel } \\
\text { generator }\end{array}$ & Offline & Pass \\
\hline ATS1 & Open & Pass \\
\hline JCI EMS & $\begin{array}{l}\text { Used to inhibit Casino AC loads until PV is } \\
\text { available to provide support. }\end{array}$ & Pass \\
\hline
\end{tabular}

Operator Activity 6: Expected results following need for diesel generator support.

Scenario: BLRMG is running in islanded mode with battery and PV supporting the load. The operator starts the manual SOE that commands the diesel generator to be connected to the BLRMG. But the MGMS is not able to synchronize the microgrid to the diesel generator. Objective: The diesel generator should start but should not connect to the BLRMG. The operator sees the below steps when the SOE starts and results are shown in Table 22.

\section{Steps:}

- MGMS should start the SOE that gets generator back online

- MGMS starts the generator.

- MGMS commands relay to close ATS1 breaker. The breaker should not close. 
Table 22 - SOE for diesel generator failure to come online with BESS

\begin{tabular}{|c|l|c|}
\hline Actor & \multicolumn{1}{|c|}{ Expected Action } & Result \\
\hline MGMS & Island Mode & Pass \\
\hline $\begin{array}{c}\text { PG\&E } \\
\text { Grid }\end{array}$ & De-energized & Pass \\
\hline Relay & Allows diesel generator start. & Pass \\
\hline PV & Stays online. & Pass \\
\hline BESS & Stays Online & Pass \\
\hline $\begin{array}{c}\text { Diesel } \\
\text { generator }\end{array}$ & Starts & Pass \\
\hline ATS1 & $\begin{array}{l}\text { Does not transfer due to lack of } \\
\text { synchronization. }\end{array}$ & Pass \\
\hline
\end{tabular}

Operator Activity 7: Expected Results following manual action to bring diesel generator online (break before make) and charge BESS.

Scenario: BLRMG is running in islanded mode with BESS and PV supporting the load. The operator starts the manual SOE that commands the diesel generator to be connected to the BLRMG.

Objective: The generator should connect to the BLRMG and BESS should start charging The operator sees the below steps when the SOE starts and results are shown in Table 23.

\section{Steps:}

- MGMS starts the generator.

- After 1 minute, MGMS commands relay to close ATS1 breaker. The breaker should close.

- The battery should now start charging. 
Table 23 - SOE for successful connection of diesel generator to islanded BLRMG with BESS

\begin{tabular}{|c|c|c|}
\hline Actor & Expected Action & Result \\
\hline $\begin{array}{l}\text { PG\&E } \\
\text { Grid }\end{array}$ & De-energized & Pass \\
\hline Relay & Allows diesel generator start. & Pass \\
\hline PV & $\begin{array}{l}\text { Trips offline. Restores } 5 \text { minutes following } \\
\text { BLRMG energization. }\end{array}$ & Pass \\
\hline BESS & $\begin{array}{l}\text { Put into stand-by until diesel generator is } \\
\text { started. Set to Island.Control = } 3 \text { following } \\
\text { diesel generator connection. Frequency shift } \\
\text { results in BESS charging from diesel } \\
\text { generator. }\end{array}$ & Pass \\
\hline $\begin{array}{c}\text { Diesel } \\
\text { generator }\end{array}$ & Starts to perform black start. & Pass \\
\hline ATS1 & $\begin{array}{l}\text { Transfers diesel generator to BLRMG when } \\
\text { voltage reaches } 95 \% \text { of nominal voltage. }\end{array}$ & Pass \\
\hline
\end{tabular}

Operator Activity 8: Expected results following BESS load share with diesel generator. Scenario: BLRMG is running in islanded mode with diesel generator powering the load and BESS charging.

Objective: To get BESS to share the load along with diesel generator To achieve the objective, the operator sets BESS frequency set-point to $61 \mathrm{~Hz}$. The operator sees the below steps once BESS frequency is set to $61 \mathrm{~Hz}$.

\section{Steps:}

- BESS starts discharging, meaning starts sharing the load.

- Generator load will be reduced. 
Table 24 - SOE for BESS load sharing with diesel generator

\begin{tabular}{|c|l|c|}
\hline Actor & \multicolumn{1}{|c|}{ Expected Action } & Result \\
\hline BESS & $\begin{array}{l}\text { BESS frequency set-point set to 61Hz to } \\
\text { share load with diesel generator }\end{array}$ & Pass \\
\hline $\begin{array}{c}\text { Diesel } \\
\text { generator }\end{array}$ & Diesel generator load reduced. & Pass \\
\hline
\end{tabular}

Operator Activity 9: Expected results following reconnection sequence.

Scenario: The BLRMG is running in islanded mode with generator, battery and PV providing the power. The PG\&E grid is now back online.

Objective: The MGMS should detect that the PG\&E grid is stable for 15 minutes and then automatically run the SOE that commands the BLRMG to go to grid connected mode.

The operator sees the below steps when the SOE starts and results are shown in Table 25.

\section{Steps:}

- After 15 minutes the MGMS should start the SOE that reconnects BLRMG back to grid connected mode

- MGMS opens the ATS1 breaker

- MGMS changes the battery's island control to 2, meaning battery should go to gridfollowing (PQ) mode.

- MGMS should command the relay to close the PCC breaker

- PV trips

- After 5 minutes, generator is turned off and PV comes online 
Table 25 - SOE for reconnection to PG\&E grid from islanded BLRMG with BESS and PV

\begin{tabular}{|c|l|c|}
\hline Actor & \multicolumn{1}{|c|}{ Expected Action } & Result \\
\hline MGMS & $\begin{array}{l}\text { Detects that the PG\&E grid has been stable } \\
\text { for 15 minutes. Executes reconnection } \\
\text { sequences. Enters grid-connection mode. }\end{array}$ & Pass \\
\hline $\begin{array}{c}\text { PG\&E } \\
\text { Grid }\end{array}$ & Energized & Pass \\
\hline Relay & Supervises closure of PCC-CB & Pass \\
\hline PCC-CB & Closed & Pass \\
\hline PV & $\begin{array}{l}\text { Trips offline and restores 5 minutes after } \\
\text { reconnection to PG\&E grid. }\end{array}$ & Pass \\
\hline BESS & Enters PQ mode, Island.Control =2 & Pass \\
\hline $\begin{array}{c}\text { Diesel } \\
\text { generator }\end{array}$ & Offline & Pass \\
\hline ATS1 & Open & Pass \\
\hline
\end{tabular}

Operator Activity 10: Expected Results after PG\&E Outage

Scenario: Operator activity 9 is completed and the BLRMG is running in grid-connected mode. The PG\&E grid has an outage. The diesel generator and BESS are available

Objective: The MGMS should automatically run the SOE that commands the BLRMG to go to islanded mode from grid connected mode, and both diesel generator and BESS share the load. The operator sees the below steps when the SOE starts and results are shown in Table 26.

\section{Steps:}

- MGMS commands the relay to trip the PCC breaker.

- MGMS starts the generator.

- After generator voltage reaches $95 \%$ of nominal, the MGMS commands relay to close ATS1 breaker. The breaker should close.

- MGMS sends island.control $=3$ to battery.

- MGMS sends frequency commands to the BESS resulting in load sharing between the generator and the battery

- PV comes online after 5 minutes. 
Table 26 - SOE for PG\&E grid outage with diesel generator and BESS available

\begin{tabular}{|c|l|c|}
\hline Actor & \multicolumn{1}{|c|}{ Expected Action } & Result \\
\hline MGMS & $\begin{array}{l}\text { Island Mode with load sharing between BESS } \\
\text { and diesel generator }\end{array}$ & Pass \\
\hline $\begin{array}{c}\text { PG\&E } \\
\text { Grid }\end{array}$ & Energized & Pass \\
\hline Relay & $\begin{array}{l}\text { Supervises opening of PCC-CB, Supervises } \\
\text { start and transfer of diesel generator }\end{array}$ & Pass \\
\hline PCC-CB & Open & Pass \\
\hline PV & $\begin{array}{l}\text { Trips offline. Restores in 5 minutes after } \\
\text { island black-start }\end{array}$ & Pass \\
\hline BESS & $\begin{array}{l}\text { After ATS1 closes, goes to islanded mode. } \\
\text { Unloaded. }\end{array}$ & Pass \\
\hline $\begin{array}{c}\text { Diesel } \\
\text { generator }\end{array}$ & Starts by MGMS & Pass \\
\hline ATS1 & $\begin{array}{l}\text { Closes after diesel generator reaches 95\% of } \\
\text { nominal voltage }\end{array}$ & Pass \\
\hline
\end{tabular}

Operator Activity 11: Expected results after induced blackout.

Scenario: The BLRMG is running in grid-connected mode. The PG\&E grid has an outage.

MGMS is not responding.

Objective: Relay should take over control and start the generator

The operator sees the below steps after a PG\&E outage.

Steps:

- Relay opens PCC breaker due to grid fault

- PV trips

- Relay waits for 15 seconds of blackout and marks MGMS offline.

- Relay starts diesel generator

- After 1 minute, when generator voltage reaches $95 \%$ of nominal, relay closes ATS1 breaker.

- Battery is in standby mode.

- After 5 minutes, PV comes online 
Table 27 - Events that would occur after a PG\&E grid outage with MGMS offline

\begin{tabular}{|c|c|c|}
\hline Actor & Expected Action & Result \\
\hline MGMS & Island Mode & Pass \\
\hline Relay & $\begin{array}{l}\text { After } 15 \text { seconds of black out, locks out } \\
\text { MGMS (LT07 = FALSE) and } \\
\text { starts diesel generator }\end{array}$ & Pass \\
\hline PCC-CB & Open & Pass \\
\hline PV & $\begin{array}{l}\text { Trips offline. Restores in } 5 \text { minutes after } \\
\text { island black-start }\end{array}$ & Pass \\
\hline BESS & $\begin{array}{l}\text { Goes to standby when PCC-CB opens } \\
\text { because Island.Control }=2\end{array}$ & Pass \\
\hline $\begin{array}{c}\text { Diesel } \\
\text { generator }\end{array}$ & Starts by SEL700GT+ relay & Pass \\
\hline ATS1 & $\begin{array}{l}\text { Closes after diesel generator reaches } 95 \% \text { of } \\
\text { nominal voltage }\end{array}$ & Pass \\
\hline
\end{tabular}

Operator Activity 12: Expected results following reconnection sequence.

Scenario: Operator Activity 11 is completed. The BLRMG is running in islanded mode with diesel generator meeting the load. The PG\&E grid is now back online. The MGMS is also back online.

Objective: The MGMS should automatically run the SOE that checks if the PG\&E grid is stable for 15 minutes and then commands the BLRMG to go to grid connected mode.

The operator sees the below steps when the SOE starts and results are shown in Table 28.

Steps:

- MGMS should start the SOE that reconnects BLRMG back to grid connected mode

- After 15 minutes, MGMS should command the relay to close the PCC breaker

- MGMS opens the ATS1 breaker

- MGMS changes the battery's island control to 2, meaning battery should go to gridfollowing (PQ) mode.

- PV trips

- After 5 minutes, generator is turned off and PV comes online 
Table 28 - SOE for reconnection from islanded BLRMG with MGMS offline earlier

\begin{tabular}{|c|l|c|}
\hline Actor & \multicolumn{1}{|c|}{ Expected Action } & Result \\
\hline MGMS & $\begin{array}{l}\text { Executes reconnection sequences. Enters grid } \\
\text { connected mode. }\end{array}$ & Pass \\
\hline $\begin{array}{c}\text { PG\&E } \\
\text { Grid }\end{array}$ & Energized & Pass \\
\hline Relay & Supervises closure of PCC-CB & Pass \\
\hline PCC-CB & Closed & Pass \\
\hline PV & $\begin{array}{l}\text { Trips offline and restores 5 minutes after } \\
\text { reconnection to PG\&E grid. }\end{array}$ & Pass \\
\hline BESS & $\begin{array}{l}\text { Synchronizes and reconnects to PG\&E grid, } \\
\text { enters PQ mode, Island.Control = 2 }\end{array}$ & Pass \\
\hline $\begin{array}{c}\text { Diesel } \\
\text { generator }\end{array}$ & Offline & Pass \\
\hline ATS1 & Open & Pass \\
\hline
\end{tabular}

Operator Activity 13: Manual black start with BESS

Scenario: The BLRMG is running in grid-connected mode and there is a PG\&E outage. The diesel generator is unavailable and the MGMS is online

Objective: The operator manually starts the SOE that commands the BLRMG to go to islanded mode from grid-connected mode and BESS to grid forming mode.

The operator sees the below steps when the SOE starts and results are shown in Table 29.

Steps:

- Manually select the SOE in MGMS that black starts with the battery

- The JCI EMS will reduce the Casino AC loads such that total load after PV support is less than $500 \mathrm{~kW}$.

- MGMS should trip the PCC breaker through the relay MGMS sends island.control $=3$ to battery.

- PV goes offline and should restore in 5 minutes 
Table 29 - SOE for manual black start with BESS

\begin{tabular}{|c|l|c|}
\hline Actor & \multicolumn{1}{|c|}{ Expected Action } & Result \\
\hline MGMS & $\begin{array}{l}\text { Island Mode, opens PCC CB and sets BESS } \\
\text { Island.Control = 3 }\end{array}$ & Pass \\
\hline $\begin{array}{c}\text { PG\&E } \\
\text { Grid }\end{array}$ & Energized & Pass \\
\hline Relay & Supervises opening of PCC-CB & Pass \\
\hline PCC-CB & Open & Pass \\
\hline PV & $\begin{array}{l}\text { Trips offline. Restores in 5 minutes after } \\
\text { island black-start }\end{array}$ & Pass \\
\hline BESS & $\begin{array}{l}\text { Black starts BLRMG by entering VF mode } \\
\text { (Island.Control =3) }\end{array}$ & Pass \\
\hline $\begin{array}{c}\text { Diesel } \\
\text { generator }\end{array}$ & Offline & Pass \\
\hline ATS1 & Open & Pass \\
\hline JCI EMS & $\begin{array}{l}\text { Used to inhibit Casino AC loads until PV is } \\
\text { available to provide support. }\end{array}$ \\
\hline
\end{tabular}




\section{Post deployment Test Cases}

After the MGMS testing and the operator training as explained in earlier sections were completed, the MGMS was deployed at the BLRMG. During onsite commissioning several issues arose that warranted additional testing at INL. The following set of systematic test cases were developed and tested to rectify the issues. Feedback was provided to SERC and Siemens to streamline efforts and reduce commissioning time and issues. The outcome of this testing effort accelerated deployment and ensured successful operation.

\subsection{Failure of BESS Frequency and Voltage Regulation by MGMS}

Objective: Verify that MGMS regulates BESS frequency and voltage when only BESS is maintaining islanded BLRMG and attempts to bring diesel generator online when there is insufficient reserve.

Initial Condition: BLRMG is operating with normal full load and is grid connected. BESS is in Auto/Economic mode, Solar PV is offline. Island.Control $=2$. BESS SOC is above $50 \%$. BESS frequency droop setting is 50\%, BESS Voltage droop setting is $10 \%$.

Step1: Reduce the load on BLRMG such that it is within the limits of BESS regulation margins of $125 \mathrm{~kW}$. With current setting of island safety margin of $75 \mathrm{kVA}$, the responsive reserve will fall below requirement of $125 \mathrm{~kW}$ when BESS is loaded greater than $300 \mathrm{~kW}$. So reduce the load to less than $300 \mathrm{~kW}$.

Step 2: Run Sequence to island the BLRMG and set island.control = 3 (Do not start diesel) Expected Result:

The PCC-CB should trip. BESS should form the grid and MGMS should maintain the BLRMG frequency at $60 \mathrm{~Hz}$, while the load on battery varies. Due to BESS model limitation the system voltage and frequency will not change no matter what (until the BESS is overloaded). So observe the frequency and voltage set points to be correct. The voltage set point is expected to be 480 volts because the RTDS ${ }^{\circledR}$ model of BESS does not produce kVAR. Ensure that the set points are sent to the RTDS ${ }^{\circledR}$. Observe system log, no relevant error messages are expected. Ensure that MOM is not committing the diesel since the SOC is good and reserve is not violated. Ensure that neither start nor stop of diesel is attempted. No switching command was sent out. Run the system in this mode for several minutes. (Minimum 5 minutes, ideally 20 minutes).

Observed Result: Same as expected result

Step 3: Increase the load on the BESS to be about $325 \mathrm{~kW}$, and keep it steady at that value. Expected Result:

As soon as the load is increased, the frequency set point should increase proportionately (verify the calculation).Voltage set point will not change because there will not be any change in BESS kVAR output. Console log should show that the MOM got triggered due to reserve violation. 
The diesel should be committed. GCON should start generator. Since the RTDS ${ }^{\circledR}$ model of generator starts quickly, in the very next cycle ATS1 close command is sent out (verify that command is received by relay). Verify that the BESS frequency set point is diesel frequency minus0.02 HZs. Since the diesel frequency of RTDS ${ }^{\circledR}$ diesel model is exactly $60 \mathrm{HZ}$, the BESS frequency set point should be such that the BESS actual frequency will be $58.98 \mathrm{~Hz}$. (Verify the calculation). Also verify that the voltage set point of 480 volts is going out. Because of sync check function of relay and since MGMS cannot influence the BESS frequency, the ATS1 will not close. Wait for 5 minutes and observe that GCON re-attempts to start the diesel all over again. Both commands are sent, start generator and close ATS1. Verify that both commands are received (no more no less). Operate two more minutes in this situation.

Observed Result: Same as expected result

Step 4: Manually set BESS island.control = 2

\section{Expected Result:}

BESS goes into standby causing blackout of BLRMG. ATS1 closes immediately. Diesel powers the BLRMG. Note that MOM may get triggered due to blackout, but the triggering of MOM should come after diesel has taken over the BLRMG. Verify that the ATS1 closed due to pending command. No new close command was issued.

Observed Result: Same as expected result

Step 5: use sequence to set BESS island.control = 3

\section{Expected Result:}

BESS comes online in grid support mode. MOM is triggered after sequence ends. MGMS resumes BESS dispatch after 30 seconds. Frequency set points are sent to BESS to do the load sharing as per new MOM schedule. Verify calculations. Continue operation for 20 minutes. Observed Result: Same as expected result

Step 6: Execute a sequence to go back to grid using break before make logic and reset island.control $=2$

Expected Result:

GCON resumes control of BESS in P/Q mode 30 seconds after the grid connection. Ensure that correct $\mathrm{kW}$ set points are sent after the new MOM schedule was created for grid-connected operation.

Observed Result: Same as expected result

\subsection{Multiple MOM Trigger by GCON}

Objective: Ensure that racing situation between MOM and GCON is resolved under SOE execution. 
Initial condition: BLRMG is operating with normal load and with grid connected. BESS is in Auto/Economic mode in GM, Solar PV is offline. Island.Control $=2$. Minimum ON and OFF time for diesel must be set to 30 minutes in MOM.

Step 1: Run an SOE that starts diesel gen, waits for some time, and then trips PCC-CB and closes ATS1 and sets island.control=3.

\section{Expected Result:}

During the entire step 1, MOM should be triggered only once by GCON after SOE successfully executed. It is possible that there is a spontaneous MOM execution due to cyclic run, but the reason should be verified to be reasonable/ logical. GCON should suspend control for 30 seconds waiting for new schedule. (This should be verified through $\log s-$ Siemens to help). Ensure that no switching command is sent out from GCON. MOM results should show the diesel to be committed. Verify through logs that no switch off command for ATS1 was attempted at any point; also verify at relay end that no switch off command was received.

Observed Result: Same as expected result

Step 2: Run SOE to shed load to make total system load below $300 \mathrm{~kW}$, and trip ATS1 via SOE. Expected Result:

GCON should restore system frequency back to $60 \mathrm{~Hz}$ quickly. No switching command is sent out or even attempt is made. Note that only BESS frequency set point should change, because of the model limitation. Voltage set point will not change, but verify that the set point goes out. New MOM schedule should show diesel offline.

It should be noted that the minimum OFF time of diesel is 30 minutes in MOM. So any action to force diesel to be ON before 30 minutes will cause infeasibility in MOM. For example, if load on BESS is increased to cause reserve violation, MOM will have to start diesel, but the minimum OFF time constraint will be violated.

Observed Result: Same as expected result

Step 3: After the system has run normally with BESS below $300 \mathrm{~kW}$, increase the load on BESS to about $325 \mathrm{~kW}$.

\section{Expected Result:}

MOM may fail or it may relax a constraint (i.e. relax min off time or reserve requirement), so we have three possible outcomes - a) MOM fails (“abort"), b) Diesel is committed, c) Diesel is kept off. In case of a) and c) nothing visible will happen. The GCON keeps regulating frequency and voltage. In case of b), GCON will NOT Switch ON diesel breaker (it may start the engine), if the diesel breaker (ATS1) was switched less than 15 minutes ago. If 15 minutes are passed from last time it switched status, it will try to switch on the ATS1.

Observed Result: Same as expected result 


\subsection{Failure to Trigger MOM by GCON during Manual Black Start}

Objective: Verify that GCON triggers MOM under manual black start.

Initial condition: BLRMG is operating with normal load and with grid connected. BESS is in Auto/Economic mode, Solar PV is offline. Island.Control = 2. The black-start sequence \#1 and \#2 are temporarily changed from auto to manual mode (or temporary disabled).

Step 1: Simulate PG\&E grid outage, and BLRMG experiences blackout.

Step 2: The SEL 700GT+ relay resumes the power by opening PCC-CB, starting diesel and closing ATS1.

\section{Expected Result:}

During the entire process, MOM should be triggered only once by GCON after the power is resumed successfully. And GCON should suspend control for 30 seconds waiting for new schedule. Since the relay has taken over MGMS, switching commands from MGMS will be ignored, but still verify from logs or from relay that no switching command was issued.

Observed Result: Same as expected result

\subsection{Export Control Failure}

Objective: Verify that export control feature works normally as tested before.

Initial condition: BLRMG is operating with normal load and with grid connected. BESS is discharging, Solar PV is offline. Island.Control $=2$. The grid export limit is set to a $-300 \mathrm{~kW}$.

Step 1: Intentionally cause mismatch between GCON export limit (-300 kW) and MOM export limit $(+100 \mathrm{~kW})$. Update the tariff to cause BESS to discharge heavily (SOC should be close to $90 \%$ ) to violate the $-300 \mathrm{~kW}$ limit. (Inconsistent export control settings should not be applied on real system @BLR)

Expected Result:

GCON reacts quickly to reduce BESS discharge to keep the import within limits.

Observed Result: Same as expected result

\subsection{Regression Test to Check the Working of SOEs}

Objective: Normal operation (i.e. SOEs that will be used in operation of BLRMG) SOEs work well.

Initial condition: BLRMG is operating with normal load and with grid connected.

Island.control $=2$

Step 1: Create SOE to black start with diesel with BESS in support mode after PG\&E grid failure. Put the SOE in automatic mode. Cause PG\&E grid failure

Expected Result: 
MGMS black starts BLRMG with diesel as primary resource and BESS in support mode. GCON smoothly transitions from grid connected operation to islanded operation without issuing or attempting to issue any switching command. MOM results in islanded mode keeping the diesel generator within limits. GCON appropriately uses MOM islanded results after taking over control after 30 second pause. Operate in islanded mode for 30 minutes minimum.

Observed Result: Same as expected result

Step 2: Create SOE to go back to grid using break before make sequence. Put the SOE in automatic mode. Bring back the PG\&E grid supply

Expected Result:

MGMS transitions the BLRMG from islanded operation to grid-connected operation smoothly. There is no switching attempt or action from GCON. MOM switches to grid-connected mode and soon after GCON takes over control in grid-connected mode of operation. Verify that MOM is triggered appropriately and GCON pauses to receive new schedules appropriately.

Observed Result: Same as expected result

\subsection{Manual MOM Failure Case}

Objective: Observe GCON behavior when MOM fails in grid connected and islanded mode Step 1: In normal islanded operation cause MOM to fail by changing the SOC limits in MOM such that the current SOC is widely outside of the SOC limits and restricting ramp rate to prevent from SOC recovery in first interval.

\section{Expected Result:}

GCON should suspend control of BESS keeping it where it is. Export control feature will also not work in this situation.

Observed Result: Same as expected result

Step 2: Restore the MOM settings to normal and manually execute MOM Expected Result:

MOM should complete successfully and GCON should resume operation normally.

Observed Result: Same as expected result

Step 3: As in Test Case 6.5 Step 1, go into islanded mode of operation, change MOM settings as in case of step 1 and cause MOM to fail.

Expected Result:

GCON suspends the control. BLRMG will operate at current set point levels, but no corrective action will be taken for reserve violation etc.

Observed Result: Same as expected result

Step 4: Reduce system load below $300 \mathrm{~kW}$ and trip diesel using SOE.

Expected Result: 
Even when MOM has failed, GCON performs voltage and frequency regulation of BESS. Verify set point calculations and making sure that set points are going out.

Observed Result: Same as expected result

Step 5: Restore the MOM settings to normal, go back to PG\&E grid using SOE

Expected Result:

GCON resumes normal operation

Observed Result: Same as expected result 


\section{Summary}

The MGMS functionalities were successfully tested using the real-time simulations and hardware-in-theloop capabilities at INL and below are some observations:

1. The MGMS was tested after all the functionalities were programmed successfully. There was a significant reduction in time and expenditure associated with the deployment, due to the 'resiliency by design' framework used at INL. This framework is currently being used in multiple future MG design projects at INL and is considered as a significant R\&D progress in microgrids.

2. The testing time could have been further reduced if we had used agile methodology where each SOE's unit and functionality testing were performed as and when the SOE was developed rather than all the SOEs at once.

3. Digital blue print approach was used to reduce commissioning and interfacing related risks, tasks, and challenges prior to the field deployment. This helped reduce the required deployment time for the MGMS to the BLRMG.

4. The rapid prototyping environment provided by the real-time environment and hardware-in-theloop helped tremendously to accelerate the development and deployment of the MGMS.

5. MGMS was interfaced with $\operatorname{RTDS}^{\circledR}$, SEL 700GT+ relay and SMA inverter. The whole system integration issues were resolved which took a significant effort.

6. Operator training was well received by the personnel at BLR as it provided an opportunity for them to operate the MGMS with live devices being controlled in real-time. Several use cases were specifically designed as do-it-yourself for the operators to get the hands-on experience of working with the MGMS prior to deployment and commissioning.

7. Customer acceptance was significantly improved due to the real-time testing results, operator training, and development of foolproof mechanisms of the overall design of the BLRMG.

8. Development and verification of the functionalities of the intertie relay controlling the BLRMG in cases where the MGMS is not responsive is regarded as a notable outcome and contribution. The demonstration of this capability added to the overall BLRMG design robustness and ensured that the facility is operational regardless of the MGMS status.

9. The operation of the DERs within the BLRMG with and without the operation plus control of the MGMS was observed to be within the prescribed IEEE 1547 limits.

10. Most technical use cases and their outcomes described in this report are verified based on the field deployment results hence validating our approach. 


\section{References}

[1] - R. Kuffel, J. Giesbrecht, T. Maguire, R.P. Wierckx, P. McLaren, "RTDS-a fully digital power system simulator operating in real time," WESCANEX 95. Communications, Power, and Computing. Conference Proceedings. IEEE May 1995

[2] - Mayank Panwar, Blake Lundstrom, James Langston, Siddharth Suryanarayanan, Sudipta Chakraborty, "An overview of real time hardware-in-the-loop capabilities in digital simulation for electric microgrids," North American Power System conference, Sep. 2013

[3] - Y. Liu, M. Steurer, S. Woodruff, P. R. Ribeiro, "A Novel Power Quality Assessment Method Using Real Time Hardware-in-the-Loop simulation,” 2004 International Conference on Harmonics and Power Quality

[4] - Nikos Hatziargyriou, Hiroshi Asano, Reza Iravani, Chris Marnay, "MicroGrids - An Overview of Ongoing Research, Development, and Demonstration Projects," IEEE power \& energy magazine, pp 7894, July-Aug. 2007

[5] - E. Limpaecher, R. Salcedo, E. Corbett, S. Manson, B. Nayak, and W. Allen, "Lessons learned from Hardware-In-the-Loop Testing of Microgrid Control Systems," Grid of the Future Symposium Cleveland, Ohio October 22-25, 2017

[6]- R.Isermann, J.Schaffnit, S.Sinsel, "Hardware-in-the-loop simulation for the design and testing of engine-control systems," Control Engineering Practice, Volume 7, Issue 5, May 1999, Pages 643-653

[7]- Yunwei Li, D. Mahinda Vilathgamuwa, Poh Chiang Loh, "Design, Analysis, and Real-Time Testing of a Controller for Multibus Microgrid System," IEEE Trans. on power electronics, vol. 19, no. 5, pp 1195-2004, Sep.2004

[8]- Jin-Hong Jeon, Jong-Yul Kim, Hak-Man Kim, Seul-Ki Kim, Changhee Cho, Jang-Mok Kim, JongBo Ahn, and Kee-Young Nam, "Development of Hardware In-the-Loop Simulation System for Testing Operation and Control Functions of Microgrid," IEEE Trans. on power electronics, vol. 25, no. 12, pp 2919-2929, Dec.2010

[9] - W. Ren, M. Steurer, T. L. Baldwin, "Improve the Stability of Power Hardware-in-the-Loop Simulation by Selecting Appropriate Interface Algorithm," IEEE Trans. Ind. Appl., vol. 44, Issue 4, pp 1286-1294, July-Aug. 2008

[10]- Cheol-Hee Yoo, Won-Jun Choi, Il-Yop Chung, Dong-Jun Won, Sung-Soo Hong, Byung-Jun Jang, "Hardware-In-the-Loop Simulation of DC Microgrid with Multi-Agent System for Emergency Demand Response", IEEE Power and Energy Society general meeting conference, 22-26 July 2012

[11] - Timo Keil, Johann Jager, “Advanced Coordination Method for Overcurrent Protection Relays Using Nonstandard Tripping Characteristics,'IEEE Trans. on power delivery, vol. 23, issue 1, pp 52-57, Dec. 2007

[12] - Pukar Mahat, Zhe Chen, Birgitte Bak-Jensen, Claus Leth Bak, "A Simple Adaptive Overcurrent Protection of Distribution Systems With Distributed Generation," IEEE Trans. on smart grid, vol. 2, issue 3, pp 428-437,June 2011 
[13]- Eric Sortomme, S. S. Venkata, Joydeep Mitra, "Microgrid Protection Using CommunicationAssisted Digital Relays," IEEE Trans. on power delivery, vol. 25, issue 4, pp 2789-2796, Dec.2009 